\title{
The fatty acid profile of rainbow trout liver cells modulates their tolerance to methylmercury and cadmium
}

Aline Ferain ${ }^{\mathrm{a}, *}$, Chloé Bonnineau ${ }^{\mathrm{a}, \mathrm{b}}$, Ineke Neefs ${ }^{\mathrm{a}}$, Jean François Rees ${ }^{\mathrm{a}}$, Yvan Larondelle ${ }^{\mathrm{a}}$, Karel A.C.De Schamphelaere $^{\mathrm{c}}$, Cathy Debier ${ }^{\mathrm{a}}$

${ }^{a}$ Institute of Life Sciences, Université catholique de Louvain, Place Croix du Sud 2/L7.05.08, B-1348 Louvain-la-Neuve, Belgium

b Irstea, UR MALY, Centre de Lyon-Villeurbanne, rue de la Doua 5/32108, F-69616 Villeurbanne, France

c Laboratory of Environmental Toxicology and Aquatic Ecology, Environmental Toxicology Unit, Ghent University, J. Plateaustraat 22, B-9000 Ghent, Belgium

*Corresponding author: E-mail addresses: aline.ferain@uclouvain.be , alineferain@hotmail.com

Received 15 November 2015, Revised 12 May 2016, Accepted 22 May 2016, Available online 23 May 2016 


\section{Highlights}

- The phospholipid composition of rainbow trout liver cells was successfully changed.

- Cell phospholipids influenced methylmercury (MeHg) and cadmium (Cd) toxicity.

- Cells enriched in 18:3n-3, 20:5n-3 or 22:5n-6 were more resistant to MeHg and Cd.

- Cell enrichment in 22:6n-3 increased resistance to Cd but not MeHg.

\section{$\underline{\text { Abstract }}$}

The polyunsaturated fatty acid (PUFA) composition of fish tissues, which generally reflects that of the diet, affects various cellular properties such as membrane structure and fluidity, energy metabolism and susceptibility to oxidative stress. Since these cellular parameters can play an important role in the cellular response to organic and inorganic pollutants, a variation of the PUFA supply might modify the toxicity induced by such xenobiotics. In this work, we investigated whether the cellular fatty acid profile has an impact on the in vitro cell sensitivity to two environmental pollutants: methylmercury and cadmium. Firstly, the fatty acid composition of the rainbow trout liver cell line RTL-W1 was modified by enriching the growth medium with either alpha-linolenic acid (ALA, 18:3n-3), eicosapentaenoic acid (EPA, 20:5n-3), docosahexaenoic acid (DHA, 22:6n-3), linoleic acid (LA, 18:2n-6), arachidonic acid (AA, 20:4n-6) or docosapentaenoic acid (DPA, 22:5n-6). These modified cells and their control (no PUFA enrichment) were then challenged for $24 \mathrm{~h}$ with increasing concentrations of methylmercury or cadmium. We observed that (i) the phospholipid composition of the RTLW1 cells was profoundly modulated by changing the PUFA content of the growth medium: major modifications were a high incorporation of the supplemented PUFA in the cellular phospholipids, the appearance of direct elongation and desaturation metabolites in the cellular phospholipids as well as a change in the gross phospholipid composition (PUFA and monounsaturated fatty acid (MUFA) levels and $n-3 / n-6$ ratio); (ii) ALA, EPA and DPA enrichment significantly protected the RTL-W1 cells against both methylmercury and cadmium; (iv) DHA enrichment significantly protected the cells against cadmium but not methylmercury; (v) AA and LA enrichment had no impact on the cell tolerance to both methylmercury and cadmium; (vi) the abundance of 20:3n-6, a metabolite of the $n-6$ biotransformation pathway, in phospholipids was negatively correlated to the cell tolerance to both methylmercury and cadmium. Overall, our results highlighted the importance of the fatty acid supply on the tolerance of fish liver cells to methylmercury and cadmium.

Keywords: Methylmercury; Cadmium; Polyunsaturated fatty acids; Fish; RTL-W1 cells; Cytotoxicity 


\section{Introduction}

The release of various pollutants in the environment, the degradation and fragmentation of habitats, the overexploitation of ecosystems as well as global warming have increased the number and intensity of external stressors on aquatic organisms (Dudgeon, 2010 and Dudgeon et al., 2006). Shifts in water quality, flow, temperature and nutrient availability are relevant examples of such stressors. By moving an organism away from its optimum performance in terms of growth and reproduction, these stressors may influence survival and fitness (Van Straalen, 2003). While many studies focus on the effect of one stressor in otherwise optimal conditions, responses to a stressor such as chemical pollution are known to be influenced by environmental conditions (e.g. temperature, nutritional status) ( Holmstrup et al., 2010).

Chemical pollutants are ubiquitous stressors that can strongly degrade aquatic ecosystems (Peters et al., 2013). Among these, methylmercury (MeHg) and cadmium (Cd) occur at elevated concentrations in many aquatic environments and can pose significant problems to organisms (Boening, 2000, Pan et al., 2010 and Rytuba, 2003). For example, anthropic release of $\mathrm{MeHg}$ and $\mathrm{Cd}$ in the environment was historically associated with human health and ecological effects in the Japanese Minamata Bay (Harada, 1995) and in the Japanese prefecture of Toyama (Sebastian and Prasad, 2014), respectively. However, the current stock of MeHg and Cd in the environment is mainly due to their direct and indirect use in numerous industrial, agricultural, medical and artistic applications, the combustion of fossil fuels and the incineration of waste (Kidd and Batchelar, 2011, McGeer et al., 2011, Pan et al., 2010 and Rytuba, 2003).

MeHg and Cd are persistent in the environment and can bioaccumulate in most aquatic organisms (Kidd and Batchelar, 2011 and McGeer et al., 2011). Whilst the aqueous route is most important for Cd exposure, the dietary route accounts for $90 \%$ of the $\mathrm{MeHg}$ exposure (Hall et al., 1997). MeHg is biomagnified throughout aquatic trophic webs (Lavoie et al., 2013 and Rolfhus et al., 2011). In fish, Cd is mainly accumulated in liver and kidneys (McGeer et al., 2011), whereas MeHg is stored in a wide variety of organs including muscle, liver, kidney, spleen, gills, intestine and brain (McGeer et al., 2011). While Cd2+ has been shown to enter cells through facilitated diffusion (McGeer et al., 2011), both passive and active transport have been suggested for MeHg cellular uptake (depending on the cell type and on the metal speciation) (Heggland et al., 2009 and Kidd and Batchelar, 2011). The two metallic compounds impair growth, reproduction and survival (Kidd and Batchelar, 2011, McGeer et al., 2011 and Sevcikova et al., 2011). They alter divalent ions metabolism, induce oxidative stress and trigger apoptosis (Kidd and Batchelar, 2011 and McGeer et al., 2011). For instance, MeHg and Cd can alter the activity of many antioxidant enzymes, decreasing the cell ability to cope with reactive oxygen species (Kidd and Batchelar, 2011, Matović et al., 2015 and McGeer et al., 2011). Oxidative attacks to lipids may lead to uncontrolled chain-reactions propagating the oxidative damage throughout cell membranes (Catalá, 2012). This is particularly the case with fatty acids with a high degree of unsaturation (polyunsaturated fatty acids (PUFAs) and highly unsaturated fatty acids (HUFAs)) as they are very prone to oxidation.

In fish, the cellular fatty acid profile of tissues such as muscle and liver is highly influenced by both dietary and environmental parameters. Firstly, the fatty acid profile globally reflects that of the diet (Bell et al., 2004, Bell et al., 2001, Bell et al., 2006, Caballero et al., 2002, Fonseca-Madrigal et al., 2005, Mourente and Bell, 2006 and Petropoulos et al., 2009). Secondly, environmental conditions such as temperature have also been reported to modulate the fish tissue fatty acid composition (Caballero et al., 2002, Snyder et al., 2012 and Wijekoon et al., 2014). These shifts may alter the organism fitness and ability to cope with additional stressors, such as chemical pollutants, as lipids play a central role in fish metabolism. Indeed, they provide metabolic energy for maintenance, growth, reproduction and locomotion, maintain the structure and function of biological membranes and are the precursors of highly bioactive molecules such as the eicosanoids (Tocher, 
2003).

As suggested by previous literature, the toxicity of MeHg and/or Cd could target cell properties modulated by PUFA content such as susceptibility to oxidative stress or membrane characteristics. The cellular lipid profile is thus likely to affect sensitivity to $\mathrm{Cd}$ and $\mathrm{MeHg}$, particularly in animals with variable lipid profiles such as fish. Despite the potential sites of interaction between lipids and pollutants, the influence of dietary lipids on metallic compounds toxicity has received little attention. A few authors have assessed whether the quality of the lipid supply can modulate the biological response to MeHg (Grotto et al., 2011, Jayashankar et al., 2012, Jin et al., 2008, Jin et al., 2007, Kaur et al., 2008, Kaur et al., 2007, Nøstbakken et al., 2012a, Nøstbakken et al., 2012b, Olsvik et al., 2011, Pal and Ghosh, 2012b and Remø et al., 2011) and Cd (Amamou et al., 2015). Overall, these authors pointed out a protective effect of fish oil and n-3 PUFAs against MeHg or Cd toxicity. In general those studies focussed on only few selected $n-3$ PUFAs and on one metallic compound. For instance, the impact of alpha-linolenic acid (ALA, 18:3n-3), eicosapentaenoic acid (EPA, 20:5n-3) and docosahexaenoic acid (DHA, 22:6n-3) has been assessed on MeHg toxicity in vitro (mouse and rat neural cells, fish and human renal cells) and in vivo (brain, plasma, liver and kidneys of rats) but not on Cd toxicity (Kaur et al., 2008 and Kaur et al., 2007; Nøstbakken et al., 2012a; Nøstbakken et al., 2012b, Pal and Ghosh, 2012a and Pal and Ghosh, 2012b). To date, the impact of $n-6$ PUFAs on metallic compounds sensitivity has received very little attention as only one study investigated the impact of arachidonic acid (AA, 20:4n-6) on the cell resistance to MeHg in fish and human renal cells ( Nøstbakken et al., 2012a). Comparisons between these studies are difficult as the models and the tested PUFAs and concentrations varied between studies.

In this study, we investigated the effect of $n-3$ and $n-6$ PUFAs on the toxicity induced by both $\mathrm{MeHg}$ and Cd, using a cellular model. Liver being an important site of interaction between lipids and metallic compounds as it is the key organ for both detoxification and fatty acid metabolism, we conducted an in vitro experiment based on rainbow trout liver cells (RTL-W1 cell line ( Lee et al., 1993)). Cells were artificially enriched with a specific PUFA from either the $n-3$ (ALA, EPA or DHA) or the $n$-6 (linoleic acid (LA, 18:2n-6), AA or docosapentaenoic acid (DPA, 22:5n-6)) pathway ( Fig. 1) before being exposed to MeHg or Cd during $24 \mathrm{~h}$. After exposure, cell viability was assessed and linked to the fatty acid profile of the cells.
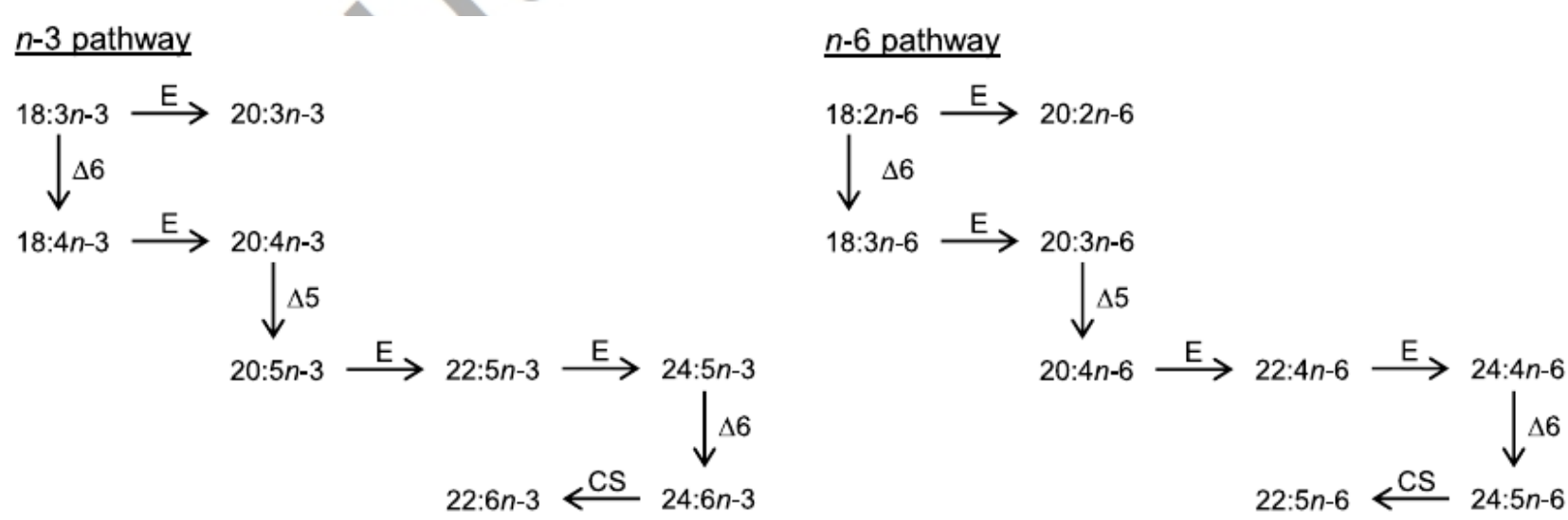

Fig. 1: Alpha-linolenic acid (left) and linoleic acid (right) biotransformation pathways in fish hepatocytes. Abbreviation used: $\Delta 5$ and $\Delta 6$, microsomal fatty acid desaturase enzyme mediated reactions; $E$, hepatic microsomal elongase mediated reactions; CS, peroxisomal fatty acid chain shortening.

\section{Material and methods}

2.1. Cells, culture media and growth conditions 
The RTL-W1 cell line derived from the liver of a 4 year old male rainbow trout (Lee et al., 1993) was kindly provided by S. Bony (INRA, France). Cells were routinely grown at $19^{\circ} \mathrm{C}$ in $75 \mathrm{~cm} 2$ flasks (Easyflasks Nunc, Life Technology, USA) containing $15 \mathrm{~mL}$ of Leibovitz's L15 medium supplemented with 5\% foetal bovine serum (FBS: PAA Laboratories, France) and 1\% antibiotics (100 IU/mL penicillin, $100 \mu \mathrm{g} / \mathrm{mL}$ streptomycin). The culture medium was renewed every two days. When $80 \%$ confluence was reached, i.e. about once a week, cells were detached with trypsin $0.125 \%$ in phosphate-buffered saline supplemented with $0.03 \%$ ethylenediamine tetraacetic acid (PBS-EDTA) before being subcultured into a new $75 \mathrm{~cm} 2$ flask. Cell counts and routine viability measurements were made on a Bürker cell in presence of Trypan Blue as an exclusion dye. Cells were regularly checked for the absence of mycoplasma (MycoAlert kit, Promega, The Netherlands).

\subsection{Experimental design}

The experimental sequence used was the following: (i) fatty acid profile manipulation during 7 days by incubating RTL-W1 cells in a medium enriched or not (control) in a specific PUFA from either the $n$-3 pathway (experimental group 1: ALA, EPA, DHA) or the $n-6$ pathway (experimental group 2: LA, AA, DPA); (ii) fatty acid profile determination of the control and PUFA-enriched cell batches; (iii) metal challenge ( $\mathrm{CH} 3 \mathrm{HgCl}$ or $\mathrm{CdCl} 2$ ) during $24 \mathrm{~h}$ and viability assessment via the CellTiter-Blue (CTB) assay (Promega, The Netherlands) and the 5-carboxyfluorescein diacetate, acetoxymethyl ester (5-CFDA,AM) assay (Life Technology, USA). This sequence was entirely repeated three times for each of the two experimental groups studied: $n$ - 3 pathway and $n-6$ pathway.

\subsection{PUFA enrichment}

The PUFAs (Larodan, Sweden) were supplied as complexes with fatty acid free-bovine serum albumin (FAFBSA) (4:1 mol:mol), as described by Best et al. (2006). When $80 \%$ confluence was reached, cells maintained in routine growth conditions were harvested with trypsin $0.0625 \%$ in PBS-EDTA and seeded at a density of 20,000 cells/cm2 in $75 \mathrm{~cm} 2$ flasks containing $15 \mathrm{~mL}$ PUFA-enriched media (50 $\mu \mathrm{M}$ of a specific $n-3$ or $n-6$ PUFA, $12.5 \mu \mathrm{M}$ FAF-BSA, 2\% FBS, 1\% antibiotics) or control medium (no PUFA, $12.5 \mu \mathrm{M}$ FAF-BSA, 2\% FBS, $1 \%$ antibiotics). The incubation lasted 7 days during which the enriched or control culture media were renewed twice. At the end of the incubation period, each cell batch was harvested with trypsin $0.0625 \%$ in PBSEDTA and subdivided into two parts of 4,000,000 living cells each: one for the fatty acid profile determination and the other one for the metal challenge.

\subsection{Fatty acid profile determination}

2.4.1. Sample preparation

The cell suspension was washed with $5 \mathrm{~mL}$ ice-cold FAF-BSA (10 g/L in Leibovitz's L15 medium) and resuspended in $2 \mathrm{~mL}$ ice-cold FAF-BSA (10 g/L in Leibovitz's L15 medium) from which $0.1 \mathrm{~mL}$ was used for protein quantification and $2 \times 0.8 \mathrm{~mL}$ were used for lipid extraction (for each sample, analyses were performed in duplicate). For protein quantification, the cell pellet was washed with L15/ex medium, a restrictive medium that contains the salts, galactose and pyruvate of Leibovitz's L15 medium at the same concentration as Leibovitz's L15 medium (Dayeh et al., 2002). Thereafter, the cell pellet was lysed (lysis buffer: 60 mM Tris, $10 \mathrm{mM}$ EDTA, 1\% sodium dodecyl sulphate (w/w) in water). The lysates were kept at $-20{ }^{\circ} \mathrm{C}$ until protein quantification by the Bicinchoninic acid (BCA) Protein Assay (Thermo Scientific Pierce, USA), with BSA as standard.

\subsubsection{Lipid extraction}

Total lipids were extracted with methanol:chloroform:water (2:2:1.8 v:v:v) as described by Bligh and Dyer (1959). A solution composed of 1,2-dipentadecanoyl-sn-glycero-3-phosphatydylcholine (Larodan, Sweden), triheptadecanoin (Larodan, Sweden) and tridecanoic acid (Larodan, Sweden) was used as internal standard.

\subsubsection{Lipid class separation}


Total lipid extracts were separated by solid phase extraction into three lipid fractions, i.e. neutral lipids, free fatty acids and phospholipids, as described by Schneider et al. (2012).

\subsubsection{Methylation and extraction}

Neutral lipid, free fatty acid and phospholipid extracts were methylated as described by Schneider et al. (2012) with minor modifications to ensure sample concentration. Briefly, eluted fractions were evaporated to dryness under a stream of $\mathrm{N} 2$ at $30{ }^{\circ} \mathrm{C}$ and methylated at $70{ }^{\circ} \mathrm{C}$ through the addition of $0.5 \mathrm{~mL}$ methanol containing $\mathrm{KOH}(0.1 \mathrm{M})$ and a $1 \mathrm{~h}$ incubation followed by the addition of $0.2 \mathrm{~mL}$ of acidified methanol $(1.2 \mathrm{M} \mathrm{HCl})$ and a 15 min incubation. The resulting fatty acid methyl esters (FAMEs) were then extracted using $1 \mathrm{~mL}$ hexane.

\subsubsection{Identification and quantification}

FAMEs were separated by gas chromatography as described by Schneider et al. (2012), with minor adaptations. The chromatograph (GC Trace-2000, Thermo Quest, Italy) was equipped with an RT2560 capillary column (100 m $\times 0.25 \mathrm{~mm}$ internal diameter, $0.2 \mu \mathrm{m}$ film thickness: Restek, USA), a GC PAL autosampler (CTC Analytics, Switzerland) and a flame ionisation detector (FID: Thermo Quest, Italy). The carrier gas used was $\mathrm{H} 2$ at constant pressure $(200 \mathrm{kPa})$ and flow rate $(2 \mathrm{~mL} / \mathrm{min})$. The FID was continuously flowed by $\mathrm{H} 2$ (35 mL/min) and air (350 mL/min) and kept at a constant temperature of $255^{\circ} \mathrm{C}$. The temperature program was as follows: an initial temperature of $80^{\circ} \mathrm{C}$, which increased at $25^{\circ} \mathrm{C} / \mathrm{min}$ up to $175^{\circ} \mathrm{C}$, a holding temperature of $175^{\circ} \mathrm{C}$ during $25 \mathrm{~min}$, a new increase at $10^{\circ} \mathrm{C} / \mathrm{min}$ up to $205^{\circ} \mathrm{C}$, a holding temperature of $205^{\circ} \mathrm{C}$ during $4 \mathrm{~min}$, a new increase at $10^{\circ} \mathrm{C} / \mathrm{min}$ up to $215^{\circ} \mathrm{C}$, a holding temperature of $215^{\circ} \mathrm{C}$ during $25 \mathrm{~min}$, a last increase at $10^{\circ} \mathrm{C} / \mathrm{min}$ up to $235^{\circ} \mathrm{C}$ and a final holding temperature of $235^{\circ} \mathrm{C}$ during $10 \mathrm{~min}$. The resulting spectra were processed with the ChromQuest software (version 4.2, ThermoFinnigan, Italy). Methyl-undecanoate (Larodan, Sweden) was used as injection standard. Peak identification and quantification were enabled by the use of an external standard, composed of 44 FAMEs (Larodan, Sweden).

2.5. Metal challenge and acute metal toxicity assessment

2.5.1. Metallic solutions

Three metallic stock solutions were prepared in cell culture grade water: $\mathrm{CH} 3 \mathrm{HgCl}$ (5 mM, CAS 115-09-3, Sigma-Aldrich, USA) and CdCl2 (30 and 100 mM, CAS 7790-78-6, Fisher Chemical, UK). Successive dilutions of these stock solutions in cell culture grade water enabled the constitution of a stock solution set for each metallic compound tested. The concentrations tested ranged from 0 to $100 \mu \mathrm{M} \mathrm{CH} 3 \mathrm{HgCl}$ and from 0 to $1000 \mu \mathrm{M} \mathrm{CdCl} 2$. These concentration ranges were selected based on preliminary tests. The working solutions were prepared fresh daily by diluting the stock solution set by 100 times in L15/ex medium.

\subsubsection{Metal challenge}

After a 7 day incubation with a specific PUFA, cells were seeded into 96-well black plates (Greiner Bio-One, Belgium), in their respective PUFA-enriched medium, at a cell density of 20,000 living cells per well. Additional wells were left empty from cells (blanks). After a minimum of $10 \mathrm{~h}$ incubation under routine growth conditions (time needed to enable cell attachment), the medium was removed and each well was exposed to one concentration of either CH3HgCl $([0-100] \mu \mathrm{M})$ or $\mathrm{CdCl} 2([0-1000] \mu \mathrm{M})$ in L15/ex medium for 24 h. Five wells with cells and two blanks were exposed to each tested concentration.

\subsubsection{Viability assays}

After $24 \mathrm{~h}$ exposure, two cell viability assays were simultaneously performed: CTB and 5-CFDA,AM, to assess the metabolic activity and the membrane integrity of the cells, respectively. CTB consists of a solution of resasurin, which is reduced in metabolically active cells into the fluorescent dye resorufin. It therefore reflects the reductase activity of the cells. 5-CFDA,AM is hydrolysed by unspecific cytosolic esterase into the fluorescent dye carboxyfluorescien. It therefore measures both the esterase activity of the cells and their membrane integrity as only an intact plasma membrane can maintain the cytosolic milieu required to support 
the esterase activity. The method described by Dayeh et al. (2005) has been slightly adapted. Briefly, the exposure medium was replaced by $120 \mu \mathrm{L}$ of a reaction mix composed of $16.7 \%$ (v:v) CTB and $0.1 \%$ (v:v) 5CFDA,AM in L15/ex medium. Directly after the reaction mix addition, the emitted fluorescence was recorded every $40 \mathrm{~s}$ during $26 \mathrm{~min}$ using the Fluoroskan Ascent FL (Thermo Electron corporation, USA) spectrofluorometer. The excitation and emission wavelengths were 530 and $590 \mathrm{~nm}$ for CTB and 435 and $530 \mathrm{~nm}$ for 5-CFDA,AM.

\subsection{Data analyses}

Graphs and statistical analyses were performed using JMP PRO 11.0 software.

\subsubsection{Fatty acid profile data analysis}

For each biological replicate, the average of the duplicates was calculated and used for further analyses. Data in the tables are reported as means (of the three biological replicates) \pm standard error of the mean. A KruskalWallis test followed by a Wilcoxon Rank Sum test were used to determine the statistical differences between the respective treatments and the control, with a total alpha set at 0.05 . A statistical difference of $\mathrm{p}<0.05$ was considered significant.

\subsubsection{Viability data analysis}

For each well, after correction of the fluorescence intensities by the blank values, the slopes of the kinetics between 0.7 and $20 \mathrm{~min}$ were determined and those with a coefficient of determination (r2) inferior to 0.85 were considered as equal to zero. The slope values were expressed in percentage of the controls (cells; $0 \mu \mathrm{M}$ metal). The averages of the five wells of the same condition were calculated for each repetition and used for data modelling. Then, for each PUFA and each metal, either a LogLogistic or a Brain \& Cousens (in case of a significant hormesis effect) model was fitted to the data from the three independent repetitions $(n=3)$ (Schabenberger et al., 1999). The EC50s and their confidence interval (at 98.3\%) were obtained by estimating the parameters of the models. Differences were considered as being significant $(\mathrm{p}<0.05)$ when no overlapping of the confidence intervals (at 98.3\%) was observed (Scheffczyk et al., 2014). Inverse predictions enabled the determination of the concentration ranges within which the response (metabolic activity or membrane integrity) was significantly different between PUFA-enriched and control cells.

\subsubsection{Multivariate analysis}

One principal component analysis was performed using, together, the fatty acid profile data (\% of the sum of the fatty acids identified in the cell phospholipids, arcsine-root square transformed) and the calculated EC50s (for MeHg and Cd). 


\section{Results}

\subsection{Lipid composition of RTL-W1 cells}

The fatty acid composition of phospholipids (Table 1), neutral lipids (Supplementary data Table S1) and free fatty acids (Supplementary data Table S2) of the RTL-W1 cells were established after one week incubation in a medium supplemented or not with $50 \mu \mathrm{M}$ PUFA (ALA, EPA, DHA, LA, AA or DPA).

\subsubsection{Lipid class separation: importance of the phospholipids}

The phospholipids accounted for $63.9-75.3 \%$ of the total cellular lipids. Free fatty acids and neutral lipids represented $17.5-22.4 \%$ and $5.0-15.1 \%$ of the total cellular lipids, respectively. Free fatty acids and neutral lipids classes were essentially composed of the saturated fatty acids (SFAs) 16:0 and 18:0. The only PUFAs found in these two fractions were the supplemented ones.

3.1.2. In vitro manipulation of the fatty acid profile of RTL-W1 cell phospholipids

The phospholipid composition of the control cells (Table 1) globally reflected that of the FBS. Both were rich in monounsaturated fatty acids (MUFAs) and SFAs, mainly 18:1n-9, 16:0 and 18:0, and low in PUFAs. Indeed, FBS was composed of 23.4\% PUFAs: 9.1\% n-3 (EPA, 22:5n-3 and DHA) and 14.4\% n-6 (LA, 20:3n-6 and AA), leading to a $n-3 / n-6$ ratio of 0.63 . Control cell phospholipids were composed of $22.1 \%$ PUFAs: $9.4 \% n-3$ (EPA, 22:5n-3 and DHA) and 12.7\% n-6 (LA, 18:3n-6, 20:3n-6 and AA), leading to a $n-3 / n-6$ ratio of 0.74.

TABLE 1 - Fatty acid profile of the RTL-W1 cells phospholipids after a 7 day-supplementation with $50 \mu \mathrm{M}$ PUFA ( $\mu \mathrm{mol} / \mathrm{g}$ proteins).

\begin{tabular}{|c|c|c|c|c|c|c|c|c|c|c|c|c|c|c|c|c|c|c|c|c|c|}
\hline \multirow{2}{*}{$\begin{array}{l}\text { Fatty acid } \\
14: 0\end{array}$} & \multicolumn{3}{|c|}{ Control } & \multicolumn{3}{|c|}{ ALA } & \multicolumn{3}{|c|}{ EPA } & \multicolumn{3}{|c|}{ DHA } & \multicolumn{3}{|c|}{ LA } & \multicolumn{3}{|c|}{ AA } & \multicolumn{3}{|c|}{ DPA } \\
\hline & 9.6 & \pm & 2.9 & 0.0 & \pm & $0.0^{*}$ & 2.9 & \pm & 2.9 & 5.7 & \pm & 2.9 & 0.0 & \pm & 0.0 * & 0.0 & \pm & $0.0^{*}$ & 2.3 & \pm & 2.3 \\
\hline $16: 0$ & 196.1 & \pm & 21.6 & 138.4 & \pm & 12.6 & 213.8 & t & 15.2 & 143.2 & \pm & 8.5 & 109.2 & \pm & 13.5 & 194.0 & \pm & 38.5 & 175.1 & \pm & 26.7 \\
\hline $18: 0$ & 104.9 & \pm & 10.1 & 97.7 & \pm & 9.6 & 114.1 & \pm & 8.7 & 65.5 & \pm & 2.5 & 70.0 & \pm & 7.5 & 111.4 & \pm & 20.6 & 93.5 & \pm & 4.5 \\
\hline Total SFA & 310.6 & \pm & 33.3 & 236.1 & \pm & 22.2 & 330.8 & 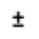 & 21.1 & 214.4 & \pm & 13.6 & 179.2 & \pm & 19.7 & 305.4 & \pm & 58.9 & 270.8 & \pm & 31.7 \\
\hline $16: 1 n-7$ & 12.8 & \pm & 4.9 & 0.0 & \pm & 0.0 & 0.0 & \pm & 0.0 & 0.0 & \pm & 0.0 & 0.0 & \pm & 0 . & 1.4 & \pm & 4 & 0.0 & \pm & 0 \\
\hline & 36.1 & \pm & 4.5 & 15.9 & \pm & $2.2^{*}$ & 25.6 & \pm & 1.6 & 11.0 & \pm & & 6.1 & \pm & & 21.8 & \pm & 3.6 & 7.0 & \pm & 7.0 * \\
\hline 18: & 276.5 & \pm & 33.7 & 107.4 & \pm & $14.1^{*}$ & 148.2 & \pm & 11.4 & 98.5 & \pm & $8.8^{*}$ & 57.6 & \pm & $4.7^{*}$ & 129.5 & \pm & $23.1^{*}$ & 97.9 & \pm & $25.6^{*}$ \\
\hline Total MUFA & 325.4 & \pm & 42.6 & 123.3 & \pm & 16.2 * & 173.7 & 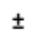 & 13.0 & 109.5 & \pm & $13.8^{\star}$ & 63.7 & \pm & $3.8^{*}$ & 152.7 & \pm & $26.7^{*}$ & 104.9 & \pm & $32.0^{*}$ \\
\hline ALA $18: 3 n-3$ & 0.0 & \pm & 0.0 & 46.4 & \pm & 29.7 * & 0.0 & \pm & 0. & 0.0 & \pm & 0.0 & 0.0 & \pm & 0. & 0.0 & \pm & 0.0 & 0.0 & \pm & 0.0 \\
\hline $20: 3$ & 0.0 & \pm & 0. & 12.0 & \pm & $1.4^{\star}$ & 0.0 & $t$ & 0 & 0.0 & \pm & 0 & 0.0 & \pm & 0. & 0.0 & \pm & 0 & 0.0 & \pm & 0.0 \\
\hline $18: 4$ & 0.0 & \pm & 0.0 & 39.8 & \pm & $8.0^{*}$ & 0.0 & \pm & 0.0 & 0.0 & \pm & 0.0 & 0.0 & \pm & & 0.0 & \pm & & 0.0 & \pm & 0.0 \\
\hline $20: 4 n-3$ & 0.1 & \pm & 0.1 & 4.0 & \pm & 4.0 & 4.0 & \pm & 4.0 & 0.0 & \pm & 0.0 & 0.0 & \pm & 0.0 & 0.0 & \pm & 0.0 & 0.0 & \pm & 0.0 \\
\hline EPA $20: 5 n-3$ & 19.9 & \pm & 2.9 & 29.6 & \pm & 4.7 & 224.3 & \pm & $14.8^{*}$ & 21.0 & \pm & 2.0 & 2.2 & \pm & $2.2^{*}$ & 0.0 & \pm & $0.0^{*}$ & 0.0 & \pm & 0.0 * \\
\hline $22: 5 n-3$ & 24.2 & \pm & 4.1 & 15.7 & \pm & 1.5 & 92.4 & \pm & $9.0 *$ & 29.6 & \pm & 2.9 & 9.7 & \pm & $1.5^{*}$ & 10.4 & \pm & 4.4 & 6.7 & \pm & $3.6^{*}$ \\
\hline DHA 22:6n-3 & 34.6 & \pm & 5.9 & 20.2 & \pm & 2.0 & 20.4 & \pm & 1.8 & 188.3 & \pm & $19.3^{\star}$ & 12.8 & \pm & 1.6 * & 9.6 & \pm & $4.2^{*}$ & 8.5 & \pm & $4.7^{*}$ \\
\hline Total n-3 PUFA & 78.8 & \pm & 12.9 & 367.7 & \pm & 48.5 * & 341.0 & \pm & $21.5^{*}$ & 238.9 & \pm & $23.9^{\star}$ & 24.7 & \pm & $4.5^{\star}$ & 20.0 & \pm & $8.6^{\star}$ & 15.2 & \pm & $8.3^{\star}$ \\
\hline LA 1 & 31.3 & \pm & 4.8 & 23.7 & \pm & 3.1 & 19.2 & \pm & & 13.0 & \pm & & 249.0 & \pm & & 16.9 & \pm & & 9.8 & \pm & 5.0 * \\
\hline $20:$ & 0.0 & \pm & 0.0 & 0.0 & \pm & 0.0 & 0.0 & \pm & 0. & 0.0 & \pm & 0.0 & 4.7 & \pm & 2.4 & 0.0 & \pm & 0 & 0.0 & \pm & \\
\hline & 2.0 & \pm & 2.0 & 0.0 & \pm & 0.0 & 0.0 & \pm & 0.0 & 0.0 & \pm & 0 & 35.3 & \pm & $3.5^{*}$ & 1.0 & \pm & 1.0 & 0.0 & \pm & 0.0 \\
\hline $20: 3 n-6$ & 20.3 & \pm & 3.0 & 2.0 & \pm & $2.0^{*}$ & 5.6 & \pm & $2.8^{*}$ & 1.8 & \pm & $1.8^{*}$ & 11.9 & \pm & 1.2 & 15.0 & \pm & 3.3 & 2.9 & \pm & $2.9^{*}$ \\
\hline AA $20: 4 n-6$ & 52.6 & \pm & 8.2 & 26.3 & \pm & $2.9^{*}$ & 31.9 & \pm & 2.2 & 14.4 & \pm & $1.1^{*}$ & 23.1 & \pm & 2.4 * & 326.6 & \pm & $53.5^{*}$ & 24.8 & \pm & $2.9^{*}$ \\
\hline $22: 4 n-6$ & 0.0 & \pm & 0.0 & 0.0 & \pm & 0.0 & 0.0 & \pm & 0.0 & 0.0 & \pm & 0.0 & 0.0 & \pm & 0.0 & 52.2 & \pm & & 0.0 & \pm & 0.0 \\
\hline DPA $22: 5 n-6$ & 0.0 & \pm & 0.0 & 0.0 & \pm & 0.0 & 0.0 & \pm & 0.0 & 0.0 & \pm & 0.0 & 0.0 & \pm & 0.0 & 0.0 & \pm & 0.0 & 327.9 & \pm & $83.3^{*}$ \\
\hline Total n-6 PUFA & 106.1 & \pm & 17.1 & 52.0 & \pm & 5.5 * & 56.7 & \pm & 3.2 & 29.1 & \pm & $2.4^{\star}$ & 324.0 & \pm & $28.3^{\star}$ & 411.7 & \pm & 67.4 * & 365.3 & \pm & 93.2 * \\
\hline Total PUFA & 184.9 & \pm & 30.0 & 419.6 & \pm & $53.4^{*}$ & 397.7 & \pm & 23.9 * & 268.0 & \pm & & 348.6 & \pm & $31.2^{\star}$ & 431.7 & \pm & $72.9^{*}$ & 380.5 & \pm & 101.4 \\
\hline Tota & 820.8 & \pm & 104.3 & 779.0 & \pm & 91.2 & 902.2 & \pm & 58.0 & 592.0 & \pm & 53.0 & 591.6 & \pm & 48.5 & 889.8 & \pm & 158.2 & 756.2 & \pm & 163.5 \\
\hline $\mathrm{n}-3 / \mathrm{n}-6$ ratio & 0.74 & \pm & 0.01 & 7.07 & \pm & 0.44 * & 6.02 & \pm & $0.27^{*}$ & 8.23 & \pm & 0.54 * & 0.08 & \pm & $0.01^{\star}$ & 0.05 & \pm & 0.02 * & 0.03 & \pm & $0.02^{*}$ \\
\hline
\end{tabular}

Data are expressed as means \pm standard error of mean $(n=3,4$ or 7$)$. Stars indicate significant differences as compared to the control (Wilcoxon Rank Sum Test, total alpha =0.05, p<0.05). Abbreviation used: ALA, alpha-linolenic acid; EPA, eicosapentaenoic acid; DHA, docosahexaenoic acid; LA, linoleic acid; AA, arachidonic acid; DPA, docosapentaenoic acid; SFA, saturated fatty acid; MUFA, monounsaturated fatty acid; PUFA, polyunsaturated fatty acid. 
Adding a specific PUFA in the culture medium for 7 days significantly changed the phospholipid composition of the RTL-W1 cells.

Firstly, the total $n$-3 PUFA content was significantly higher in the phospholipids of the cells incubated with a specific $n$-3 PUFA ( $<$ 0.05), while $n$-6 PUFAs were significantly more abundant in the phospholipids of the cells incubated with a specific $n-6$ PUFA ( $<<0.05$ ). In addition, the phospholipids of the cells enriched in $n-3$ PUFAs contained significantly less $n-6$ PUFAs than those of the control cells $(p<0.05)$. This trend was however not significant in the EPA-enriched cells $(\mathrm{p}=0.068)$. Similarly, the amount of $n$-3 PUFAs was significantly lower in the phospholipids of the cells enriched in $n-6$ PUFAs than in the phospholipids of the control cells $(\mathrm{p}<0.05)$. As a result, the $n-3 / n-6$ ratio was significantly higher (by around 10 times) in the $n-3$ PUFA-enriched cells than in the control cells $(\mathrm{p}<0.05)$ and significantly lower (by around 10-20 times) in the $n$-6 PUFA-enriched cells, as compared to the control cells $(\mathrm{p}<0.05)$. The total PUFAs found in the cellular phospholipids significantly increased $(\mathrm{p}<0.05)$ in cells supplemented with ALA, EPA, LA and AA while this increase was not significant in DHA- $(p=0.172)$ and DPA-enriched cells $(p=0.068)$. Besides, the total MUFAs found in the phospholipids significantly dropped (between 47-80\% drop) in each PUFA-treated cell batch ( $\mathrm{p}<0.05$ ), mainly due to a significant drop in 18:1n-9, but without significance in the EPA-enriched cells $(p=0.068)$. By contrast, both the total SFAs and the total phospholipid levels remained similar in each experimental condition.

Secondly, a significant increase of the amount of the specific PUFA added into the cell culture media was observed (from 188.3 up to $327.9 \mu \mathrm{mol} / \mathrm{g}$ protein) in the phospholipids of all enriched cells ( $\mathrm{p}<0.05$ ), allowing the supplemented PUFA to become the main fatty acid within this fraction, accounting for $26-49 \%$ of the total phospholipids.

Thirdly, the amount of biotransformation products most supposedly derived from the supplemented PUFA increased in all enriched cells, indicating the presence of a bioconversion process via direct elongation and desaturation (see Fig. 1 for the biotransformation pathways). The 18:4n-3 and 18:3n-6 levels significantly increased in cells respectively supplemented with ALA and LA ( $p<0.05)$, suggesting the occurrence of a $\Delta 6$ desaturase activity in the RTL-W1 cells. Direct elongation products of ALA, EPA and AA, i.e. 20:3n-3, 22:5n-3 and 22:4n-6, also significantly increased in cells enriched in these PUFAs ( $p<0.05$ ). Similarly, traces of 20:2n6 were found in the LA-enriched cells. However, the amounts of the biotransformation products, resulting from a second step of elongation/desaturation were not different between enriched and control cells, indicating no further elongation and desaturation of the six above-mentioned metabolites.

Fourthly, the cells supplemented with a specific $n-6$ PUFA were significantly lower in the $n-3$ PUFAs EPA, 22:5n-3 and DHA, than the control cells $(\mathrm{p}<0.05)$. This trend was however not significant for 22:5n-3 in the AA-enriched cells $(\mathrm{p}=0.073)$.

Finally, most treatments affected the cellular levels of the n-6 PUFAs LA, 20:3n-6 and AA. Indeed, the amount of LA was lower in cells enriched in DHA, AA and DPA than in the control cells $(p<0.05)$. This trend was however not significant in AA-enriched cells ( $p=0.073)$. In addition, the AA level was lower in cells enriched in ALA, DHA, LA and DPA than in the control cells $(p<0.05)$. Besides, the levels of 20:3n-6 were lowered by a factor of 10.2, 3.6, 11.3 and 9 in cells respectively supplemented with ALA, EPA, DHA and DPA, as compared to the control cells $(\mathrm{p}<0.05)$. A similar trend was observed in LA-enriched cells but without significance $(p=0.068)$. 


\subsection{RTL-W1 cells response to an acute metal challenge}

After one week of incubation with a specific PUFA, enriched and control cells were challenged for $24 \mathrm{~h}$ with increasing concentrations of MeHg or Cd in a serum- and PUFA-free medium. The cell viability was assessed by measuring simultaneously the metabolic activity (CTB assay, Fig. 2 and Fig. 3) and the membrane integrity (5-CFDA,AM assay, Supplementary data Fig. S1 and Fig. S2) of the cells. The two metallic compounds caused a dose-dependent decline in cell viability, regardless of the PUFA-enrichment or the toxicity test.

\subsubsection{ALA, EPA, DHA and DPA: four PUFAs increasing the cell tolerance to MeHg and/or Cd}

The enrichment in ALA, EPA and DPA significantly increased the cell tolerance to MeHg as measured through the metabolic activity. Indeed, the dose-response curves were shifted to the right for cells enriched in these three PUFAs, compared to the control cells (Fig. 2a,b and Fig. 3c). Based on the dose-response models, the metabolic activity of ALA-, EPA- and DPA-enriched cells was significantly higher than that of the control cells for the respective MeHg concentration ranges [0.39-11.47], [0.13-8.83] and [0.24-3.17] $\mu \mathrm{M}(\mathrm{p}<0.05)$ (Fig. 2a,b and Fig. 3c). Besides, the calculated MeHg EC50s were respectively 4.0, 4.5 and 3.2 times higher for cells enriched in ALA, EPA and DPA than the MeHg EC50 for the control cells (p<0.05) (Table 2).

Table 2. EC50s of MeHg and Cd for metabolic activity (as measured by the CTB assay) in RTL-W1 cells enriched in different fatty acids. The EC50s and their confidence interval (at 98.3\%) were obtained by estimating the parameters of the LogLogistic models, which were fitted to the data from the three independent repetitions $(\mathrm{n}=3)$. Abbreviation used: MeHg, methylmercury; EC50, median effect concentration; Cd, cadmium; PUFA, polyunsaturated fatty acid; ALA, alpha-linolenic acid; EPA, eicosapentaenoic acid; DHA, docosahexaenoic acid; LA, linoleic acid; AA, arachidonic acid; DPA, docosapentaenoic acid

The enrichment in ALA, EPA, DHA and DPA increased the cell tolerance to Cd assessed through the metabolic activity. Indeed, based on the dose-response models, ALA-, EPA-, DHA- and DPA-enriched cells were significantly more metabolically active than the control cells for the Cd concentration ranges [35.8-555.6], [36.6-331.8], [67.0-191.6] and [0.1-39.6] $\mu \mathrm{M}$, respectively $(\mathrm{p}<0.05)$ (Fig. 2d-f and Fig. 3f). The calculated Cd EC50 s were respectively 3.0, 2.9 and 1.9 times higher for cells enriched in ALA, EPA and DHA than for the control cells $(p<0.05)$ (Table 2). While the DPA enrichment did not significantly affect the Cd EC50 (Table 2), it induced a hormesis effect, i.e. a beneficial effect at low Cd dose (Fig. 3f). The hormesis term of the parametrisation of the Brain \& Cousens model (Schabenberger et al., 1999) was significant: 2.30 [0.57-4.88)] (Supplementary data Table S4).

The DPA supplementation significantly increased the cell tolerance to both MeHg and Cd evaluated through measuring the membrane integrity. Indeed, as for the CTB assay, we observed, for the 5-CFDA,AM assay, a shift to the right of the dose-response curves for the DPA-enriched cells compared to the control cells (Supplementary data Fig. S2c,f). Based on the dose-response models, the membrane integrity in the DPAenriched cells was significantly higher than in the control cells after exposure to MeHg concentrations ranging from 1.41 to $5 \mu \mathrm{M}$ and to Cd concentrations ranging from 10.8 to $126.3 \mu \mathrm{M}(\mathrm{p}<0.05)$ (Supplementary data Fig. S2c,f). The calculated MeHg and Cd EC50 values increased respectively by 2.0 and 1.5 times in comparison to the controls in case of a MeHg or Cd challenge $(\mathrm{p}<0.05)$ (Supplementary data Table S3). The other PUFAs had no impact on the viability decline (in terms of membrane integrity) caused by either MeHg or Cd (Supplementary data Figs. S1 a,b,d,e and S2 a,b,d,e). 

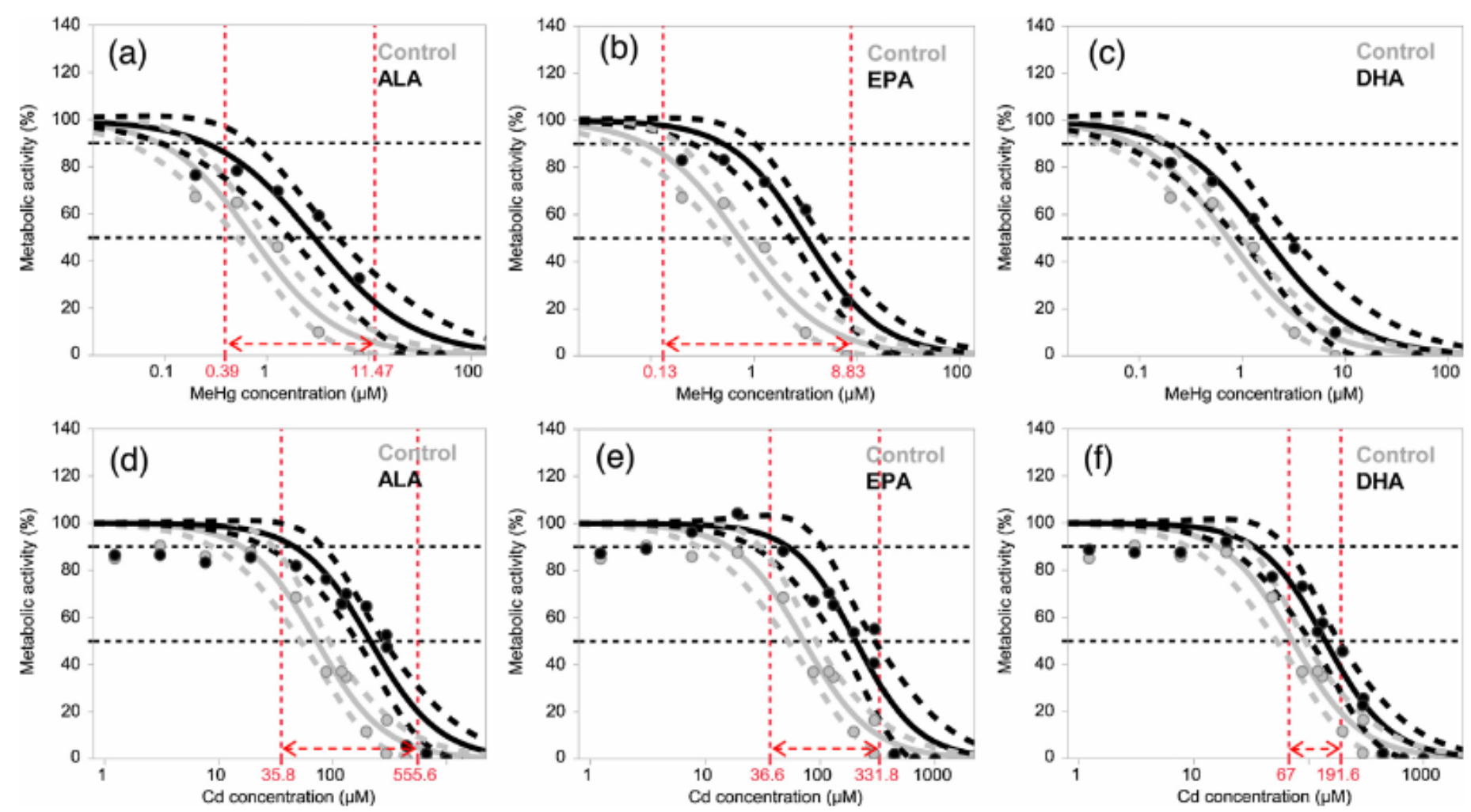

Fig. 2: Metabolic activity of the RTL-W1 cells enriched (black) or not (grey) in a specific n-3 PUFA (ALA, EPA or DHA) and challenged with increasing concentrations of $\mathrm{MeHg}(\mathrm{a}-\mathrm{c})$ or $\mathrm{Cd}(\mathrm{d}-\mathrm{f})$ during $24 \mathrm{~h}$. Plain curves represent the LogLogistic prediction models; dotted curves represent the confidence intervals at $98.3 \%$ for the predictions. Pointsrepresent the mean metabolic activities of the cells challenged at specific $\mathrm{MeHg}$ or Cd concentrations $(n=3)$. The dotted arrows delimit the metal concentration ranges withinwhich the predicted metabolic activity of cells enriched with a specific n-3 PUFA is significantly higher than that of the control cells. Abbreviation used: ALA, alpha-linolenicacid; EPA, eicosapentaenoic acid; DHA, docosahexaenoic acid; MeHg, methylmercury; Cd, cadmium.
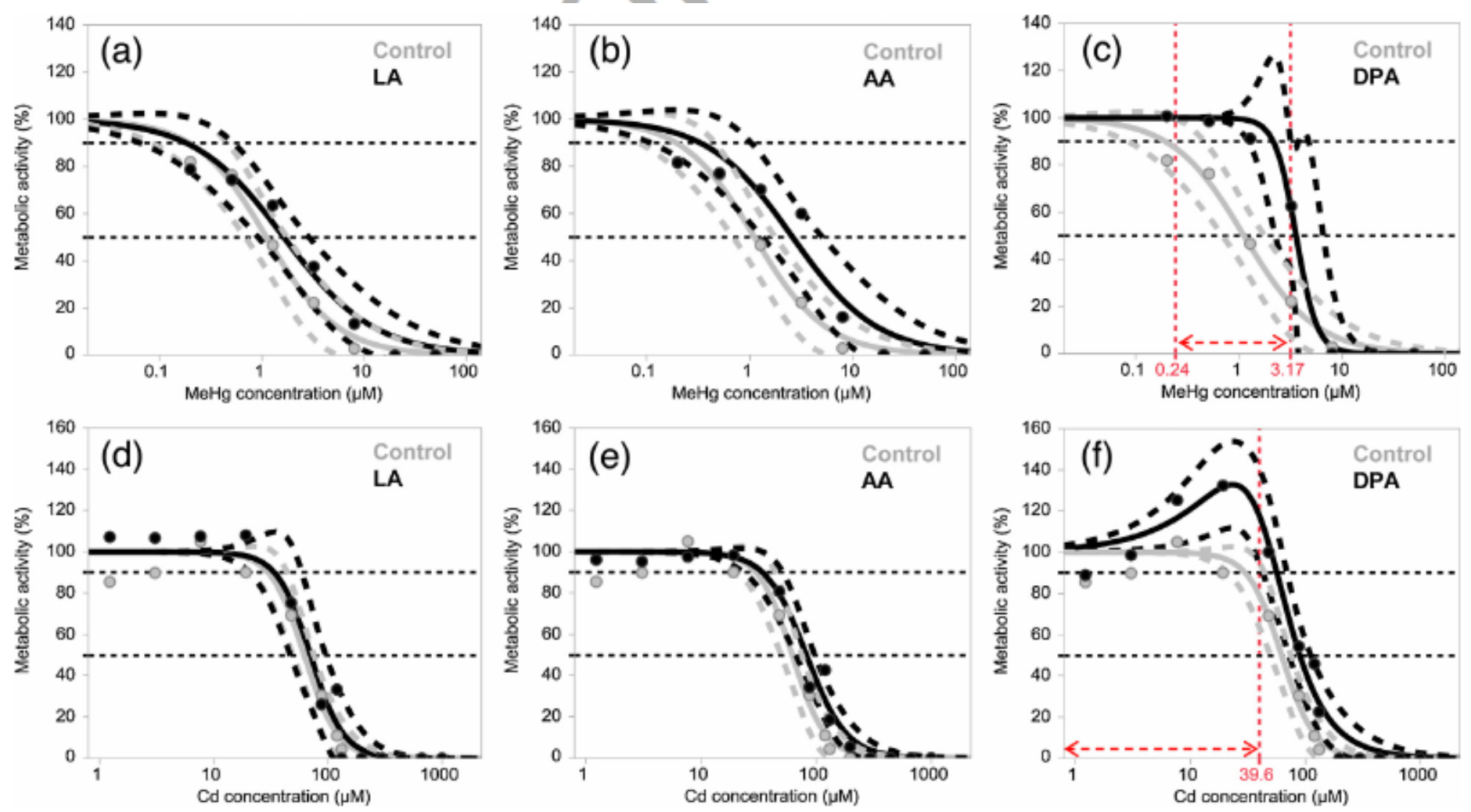

Fig. 3: Metabolic activity of the RTL-W1 cells enriched (black) or not (grey) in a specific n-6 PUFA (LA, AA or DPA) and challenged with increasing concentrations of $\mathrm{MeHg}(a-c)$ or $\mathrm{Cd}(d-f)$ during $24 \mathrm{~h}$. Plain curves represent the LogLogistic or Brain \& Cousens prediction models; dotted curves represent the confidence intervals at 98.3\% for thepredictions. Points represent the mean metabolic activities of the cells challenged at specific $\mathrm{MeHg}$ or $\mathrm{Cd}$ concentrations ( $n=3$ or 4 ). The dotted arrows delimit the metalconcentration ranges within which the predicted metabolic activity of cells enriched with a specific n-6 PUFA is significantly higher than that of the control cells. Abbreviationused: LA, linoleic acid; AA, arachidonic acid; DPA, docosapentaenoic acid; MeHg, methylmercury; Cd, cadmium. 
TABLE 2 - EC50s of MeHg and Cd for metabolic activity (as measured by the CTB assay) in RTL-W1 cells enriched in different fatty acids. The EC50s and their confidence interval (at 98.3\%) were obtained by estimating the parameters of the LogLogistic models, which were fitted to the data from the three independent repetitions ( $\mathrm{n}=3$ ). Abbreviation used: MeHg, methylmercury; EC50, median effect concentration; Cd, cadmium; PUFA, polyunsaturated fatty acid; ALA, alpha-linolenic acid; EPA, eicosapentaenoic acid; DHA, docosahexaenoic acid; LA, linoleic acid; AA, arachidonic acid; DPA, docosapentaenoic acid

\begin{tabular}{|c|c|c|c|c|c|c|}
\hline \multirow[b]{2}{*}{$\begin{array}{c}\text { PUFA } \\
\text { enrichment }\end{array}$} & \multicolumn{3}{|c|}{$\mathrm{MeHg}$ EC50 } & \multicolumn{3}{|c|}{ Cd EC50 } \\
\hline & $\begin{array}{l}\text { Estimation } \\
\qquad(\mu \mathrm{M})\end{array}$ & $\begin{array}{c}\text { Confidence } \\
\text { interval }(\mu \mathrm{M})\end{array}$ & $\begin{array}{l}\text { Fold change } \\
\text { (compared to } \\
\text { the control) }\end{array}$ & $\begin{array}{l}\text { Estimation } \\
\qquad(\mu \mathrm{M})\end{array}$ & $\begin{array}{l}\text { Confidence } \\
\text { interval }(\mu \mathrm{M})\end{array}$ & $\begin{array}{l}\text { Fold change } \\
\text { (compared to } \\
\text { the control) }\end{array}$ \\
\hline Control n-3 & 0.73 & {$[0.51-1.01]$} & 1.0 & 72.5 & [52.3 - 94.6] & 1.0 \\
\hline ALA & 2.90 & [1.66 - 4.79] & 4.0 & 214.7 & [161.7 - 275.8] & 3.0 \\
\hline EPA & 3.25 & [2.22 - 4.61] & 4.5 & 207.0 & [144.2 - 290.1] & 2.9 \\
\hline $\mathrm{DHA}$ & 1.68 & [0.92 - 2.92] & 2.3 & 140.3 & [102.5 - 182.3] & 1.9 \\
\hline Control n-6 & 1.11 & {$[0.70-1.72]$} & 1.0 & 62.3 & [49.8 - 75.7] & 1.0 \\
\hline LA & 1.65 & {$[0.92-2.79]$} & 1.5 & 70.6 & [49.9 - 95.6] & 1.1 \\
\hline$A A$ & 2.62 & [1.31-4.80] & 2.4 & 82.7 & [68.2 - 98.0] & 1.3 \\
\hline DPA & 3.58 & {$[2.50-5.14]$} & 3.2 & 89.7 & {$[72.5-110.6]$} & 1.4 \\
\hline
\end{tabular}

\subsection{Multivariate analysis}

In order to highlight relationships between the phospholipid composition of the RTL-W1 cells and their resistance to $\mathrm{MeHg}$ and $\mathrm{Cd}$, we performed a principal component analysis with data from both the fatty acid profile (phospholipid fraction) and the metal challenge (calculated EC50s for MeHg and Cd). The three first principal components (PC) explained 58.9\% of the total variance. PC1, PC2 and PC3 explained 24.1, 19.7 and $15.1 \%$ of the total variance, respectively (Table 3, Fig. 4). The three first components clearly separated the PUFA-enriched groups from each other and from the controls (Fig. 4). The first axis of the principal component analysis separated cells with a high resistance to both $\mathrm{MeHg}$ and $\mathrm{Cd}$ from less resistant cells while the second and the third axes separated cells with a higher tolerance to MeHg from those more tolerant to Cd (Fig. 4). The higher resistance to both MeHg and Cd was associated with a high phospholipid content in $n$-3 PUFAs, mainly ALA, 18:4n-3 and 20:3n-3 (PC1) and a lower phospholipid content in n-6 PUFAs, mainly 20:3n-6, LA, 18:3n-6 and 20:2n-6 (PC1, PC2, PC3) ( Table 3). Besides, some fatty acids were specifically associated with a higher resistance to one metallic compound only. Indeed, a higher phospholipid content in $n-3$ HUFAs, mainly EPA, 22:5n-3 and DHA, was associated with a higher cellular resistance to Cd (PC2) but not to MeHg (PC3) ( Table 3). In contrast, a higher phospholipid content in n-6 HUFAs, mainly DPA, 22:4n-6 and AA, was associated with a higher cellular resistance to MeHg (PC3) but not to Cd (PC2) ( Table 3). Finally, a higher phospholipid content in both MUFAs (mainly 18:1n-9 and 16:1n-7) and SFAs (mainly 16:0 and 14:0) was associated in PC1 with a lower resistance to both MeHg and Cd ( Table 3). However, the opposite relationship was observed with both MUFAs and SFAs in PC2 and with SFAs in PC3. Indeed, a higher phospholipid content in both MUFAs (e.g. 18:1n-9) and SFA (e.g. 16:0) was linked to a higher resistance to Cd (PC2) ( Table 3). In addition, a higher phospholipid content in SFAs (e.g. 16:0) was associated to a higher resistance to MeHg (PC3). These contradictions reduce the plausibility of a preponderant role of the MUFA phospholipid level in modulating the toxicity of MeHg, on the one hand, and of the SFA phospholipid level in modulating the toxicity of both MeHg and Cd, on the other hand. 
TABLE 3 - Principal component analysis loadings.

\begin{tabular}{lrrr} 
& & & \\
\cline { 2 - 4 } & PC1 & PC2 & PC3 \\
\hline $14: 0(1)$ & -0.46 & 0.58 & 0.12 \\
$16: 0(2)$ & -0.49 & 0.50 & -0.56 \\
$18: 0(3)$ & 0.00 & -0.08 & -0.39 \\
$16: 1 \mathrm{n}-7(4)$ & -0.54 & 0.30 & 0.16 \\
$18: 1 \mathrm{n}-7(5)$ & -0.35 & 0.45 & 0.25 \\
$18: 1 \mathrm{n}-9(6)$ & -0.60 & 0.60 & 0.02 \\
ALA (7) & 0.81 & 0.07 & 0.21 \\
$20: 3 \mathrm{n}-3(8)$ & 0.81 & 0.07 & 0.21 \\
$18: 4 n-3(9)$ & 0.81 & 0.08 & 0.21 \\
$20: 4 n-3(10)$ & 0.39 & 0.29 & 0.17 \\
EPA (11) & 0.26 & 0.74 & 0.22 \\
$22: 5 n-3(12)$ & 0.05 & 0.72 & 0.32 \\
DHA (13) & -0.09 & 0.48 & 0.24 \\
LA (14) & -0.14 & -0.54 & 0.76 \\
$20: 2 n-6(15)$ & -0.08 & -0.56 & 0.62 \\
$18: 3 n-6(16)$ & -0.16 & -0.66 & 0.64 \\
$20: 3 n-6(17)$ & -0.72 & -0.16 & 0.31 \\
AA (18) & -0.27 & -0.40 & -0.41 \\
22:4n-6 (19) & -0.15 & -0.44 & -0.44 \\
DPA (20) & 0.13 & -0.24 & -0.56 \\
EC50 MeHg & 0.70 & -0.20 & -0.49 \\
EC50 Cd & 0.83 & 0.43 & 0.09 \\
\hline Part of the total variance explained (\%) & 24.10 & 19.70 & 15.10 \\
Cumulative part of the variance explained (\%) & 24.10 & 43.80 & 58.90 \\
\hline
\end{tabular}

The principal component analysis was performed using, together, the fatty acid profile data (expressed as percentages of the sum of the fatty acids identified in the cell phospholipids, arcsine-root square transformed) and the calculated EC50s (for MeHg and Cd). A loading is the correlation between one variable and one principal component. Numbers in brackets refer to the eigenvectors representation used in the biplot (see Fig. 3). Abbreviation used: PC, principal component; ALA, alpha-linolenic acid; EPA, eicosapentaenoic acid; DHA, docosahexaenoic acid; LA, linoleic acid; AA, arachidonic acid; DPA, docosapentaenoic acid; EC50, median effect concentration; $\mathrm{MeHg}$, methylmercury; Cd, cadmium. 


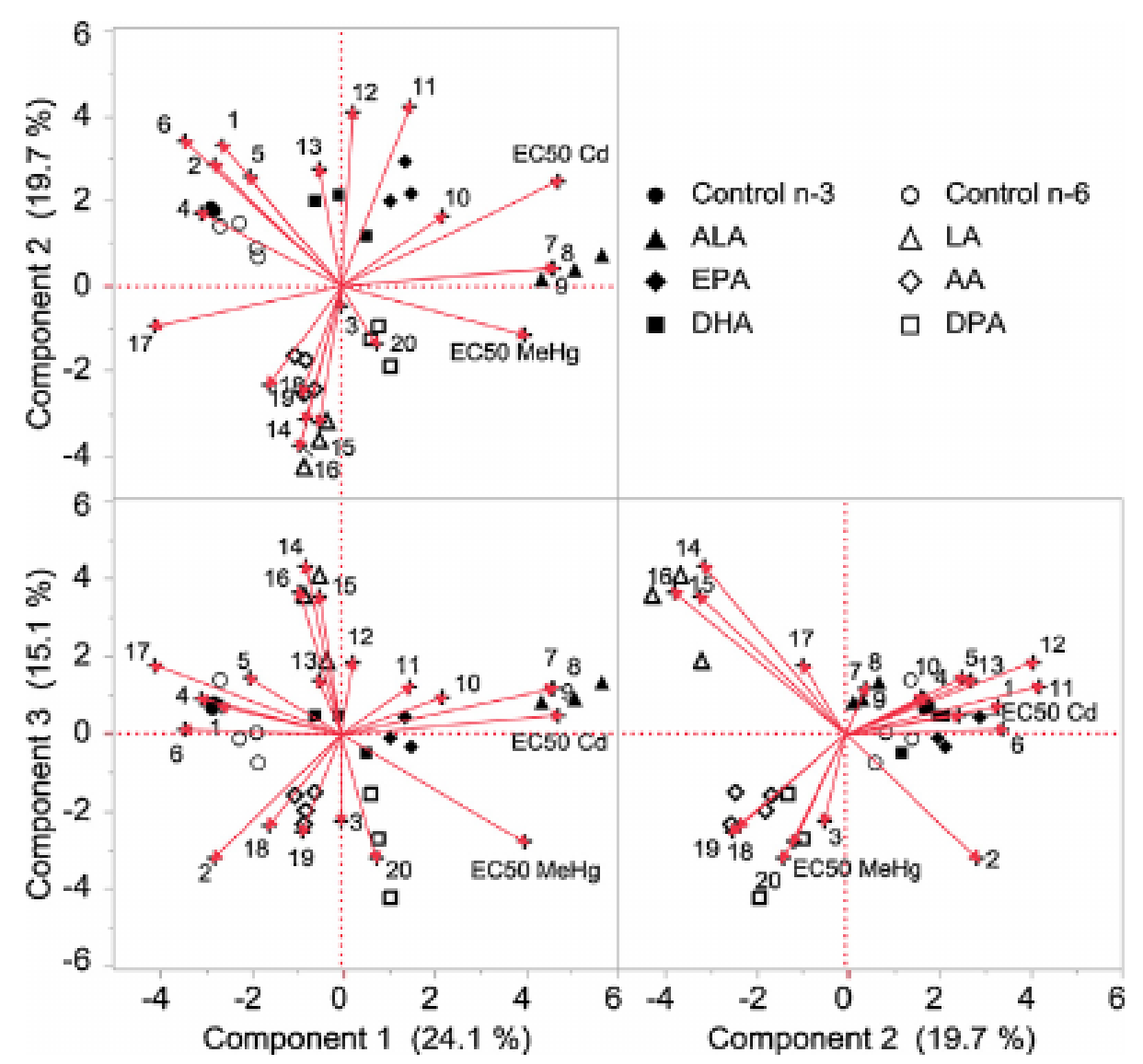

Fig. 4: Principal component analysis biplot. The principal component analysis wasperformed using, together, the fatty acid profile data (expressed as percentages ofthe sum of the fatty acids identified in the cell phospholipids, arcsine-root squaretransformed) and the calculated EC50s (for MeHg and Cd). Numbers associated to theeigenvectors refer to a specific fatty acid that composed the cellular phospholipids(see Table 3). Abbreviation used: ALA, alpha-linolenic acid; EPA, eicosapentaenoicacid; DHA, docosahexaenoic acid; LA, linoleic acid; AA, arachidonic acid; DPA, docos-apentaenoic acid; EC50, median effect concentration; MeHg, methylmercury; Cd,cadmium.

\section{Discussion}

In the present study, we successfully modulated the phospholipid composition of the RTL-W1 cells and highlighted the correlation between that phospholipid composition and cell sensitivity to MeHg and Cd.

The lipid composition of fish tissues is known to globally reflect that of the diet (Bell et al., 2004, Bell et al., 2001, Bell et al., 2006, Caballero et al., 2002, Fonseca-Madrigal et al., 2005, Mourente and Bell, 2006 and Petropoulos et al., 2009). Similarly, the phospholipid composition of in vitro cultured fish cells globally reflects that of the growth media ( Tocher et al., 1988). This property was successfully used in the literature ( Gregory et al., 2011, Tocher, 1990 and Tocher and Dick, 1990) and in the present study to change the phospholipid composition of fish cells. Cells differing in their phospholipid composition but from the same origin can thus be obtained by changing their lipid supply.

The PUFA supplementation had no impact either on the proportions of the three cellular lipid classes analysed or on the total lipid content of the cells: cellular lipids were mainly phospholipids and the total phospholipid content was kept constant independently of the PUFA treatment applied. Similar observations were made in the Atlantic salmon cell line (AS) supplemented with $25 \mu \mathrm{M}$ ALA or LA (Tocher and Dick, 1990). This result indicates that the modification of the phospholipid composition of the RTL-W1 cells resulted from phospholipid turnover rather than from phospholipid accumulation. This turnover was rather efficient as at least $30 \%$ of the cellular phospholipid composition was significantly changed after one week of PUFA 
supplementation. Major changes observed included a high integration of the supplemented PUFA in the cellular phospholipids, the occurrence of direct elongation and desaturation metabolites in the cellular phospholipids as well as a modification of the gross phospholipid composition (MUFA and PUFA levels as well as $n-3 / n-6$ ratio). The high integration of the supplemented PUFA is in accordance with previous literature ( Buzzi et al., 1996, Gregory et al., 2011 and Tocher, 1990) and corroborates the importance of the lipid composition of the growth media in defining the phospholipid composition of fish cell culture.

Freshwater fish such as rainbow trout are known to be able to synthesize EPA and DHA from ALA (Buzzi et al., 1996, Fonseca-Madrigal et al., 2005 and Mourente and Tocher, 1998). However, no significant increase of the EPA and DHA levels was observed after ALA supplementation. Instead, we observed a significant accumulation of its direct desaturation and elongation metabolites (18:4n-3 and 20:3n-3), which were not shown to accumulate in vivo ( Tocher, 2003). Similarly, the supplementation with EPA led to a significant accumulation of its elongation metabolite (22:5n-3) while no significant increase of DHA was observed. Similar observations were made in cells enriched in the $n-6$ PUFAs LA and AA as expected since the biotransformation of $n-3$ and $n-6$ fatty acids requires the same enzymes ( Tocher, 2003). The supplementation with LA was associated with an increase of the phospholipid levels of its desaturation (18:3n-6) and elongation (20:2n-6, in traces) metabolites without any change in the phospholipid levels of AA and DPA. Likewise, the supplementation with AA led to the accumulation of its elongation metabolite (22:4n-6) while no increase of DPA was observed. The reduction of the ability to synthetize significant amounts of valuable HUFAs such as EPA, DHA and AA from their respective precursors ALA and LA has been already observed after long-term fish cell culture ( Gregory et al., 2011, Tocher, 1990 and Tocher and Dick, 1990). While this low in vitro biotransformation capacity could be disadvantageous when attempting to reproduce in vivo conditions, it is interesting as it allows studies of the biological role of the HUFA-precursors ALA, EPA and LA, independently from their indirect role as HUFA-providers.

In the present study, we used the RTL-W1 cell line to assess the impact of individual PUFAs on fish liver cells sensitivity to MeHg and Cd. Our results indicate that enrichment in specific PUFAs was associated with an increase in cell resistance to MeHg (ALA, EPA, DPA) and Cd (ALA, EPA, DHA, DPA). The protective impact of these PUFAs might have occurred through (i) the decrease of the metal cellular uptake due to modifications of membrane lipid composition and/or (ii) the modulation of intracellular parameters increasing the cell resistance to the damages induced by metals.

Modifications of the lipid composition of biological membranes is likely to influence its permeability, fluidity and functions such as ion transport (Arts and Kohler, 2009 and Tillman and Cascio, 2003). Since Cd2+ uptake occurs through transport pathways of essential metals, its absorption efficiency might be affected by modifications of membrane properties (Klinck and Wood, 2011 and McGeer et al., 2011). However, to our knowledge, the influence of the membrane lipid composition on cellular Cd uptake has never been investigated yet.

Changes in membrane properties might also influence both active and passive MeHg transport. In particular, the degree of unsaturation of the membrane modulates its fluidity, which in turn might influence its permeability to pollutants. Indeed, DHA supplementation has been found to decrease MeHg uptake in some mammalian cell lines such as the human embryonic kidney cell line (HEK293) (Nøstbakken et al., 2012a) and the rat C6-glial cell line (Kaur et al., 2007) and in primary cultures of cerebellar neurons and astrocytes from mice (Kaur et al., 2008). However, DHA supplementation had no significant effect on MeHg uptake in the Atlantic salmon kidney cell line (ASK) (Nøstbakken et al., 2012a) and in the rat B35-neuronal cell line (Kaur et al., 2007). Similarly, EPA supplementation had no impact on MeHg uptake in both the ASK and HEK293 cell lines. The role of the fatty acid supplementation on cellular uptake of metals remains poorly known. Consequently, further studies are 
necessary to better understand the role of the membrane lipid composition in MeHg and Cd uptake and to determine whether the protective effect of specific PUFA enrichment against MeHg or Cd toxicity can be attributed to a decrease of the metal uptake.

The toxicity of MeHg and Cd is mainly triggered by the induction of oxidative stress and the alteration of the ionic balance (e.g. calcium), which can lead to apoptosis (Kidd and Batchelar, 2011, Matović et al., 2015 and McGeer et al., 2011). The supplementation with n-3 PUFAs (ALA, EPA and DHA) might have increased the RTL-W1 cell ability to cope with these adverse effects. In addition, the fact that each fatty acid treatment exerted similar factors of protection against both metals ( Table 2) suggests similar mechanisms of protection (Table 4)

Firstly, the supplementation with $n$-3 PUFAs could have counteracted the oxidative stress induced by the metals, either directly by decreasing reactive oxygen species production or indirectly by enhancing the cellular antioxidant defences. For example, MeHg and $\mathrm{Cd}$ are known to directly increase the mitochondrial production of reactive oxygen species by decreasing the activity of the complex IV and III of the transport electron chain, respectively ( Cambier et al., 2009 and Wang et al., 2004) while $n$-3 PUFAs can increase both of them ( Hagopian et al., 2010), and thus might counteract the negative impact of these metals. Besides, both MeHg and $\mathrm{Cd}$ are generally known to decrease the cellular antioxidant defences by decreasing both the reduced glutathione cellular level and the antioxidant enzyme activities. This results from their high affinity for thiol groups, their affinity for (MeHg) or similarity with (Cd) the cofactors (e.g. manganese, selenium) of some of antioxidant enzymes or their direct interactions with the catalytic sites (Cd) of some antioxidant enzymes ( Casalino et al., 2002, Farina et al., 2011, Matović et al., 2015 and Wang et al., 2015). The dietary supplementation with ALA (1\%) was reported to counteract the toxic effect of a MeHg contaminated diet ( $5 \mathrm{mg} / \mathrm{kg}$ body weight) by restoring the antioxidant defences and reducing lipid peroxidation in liver, kidneys, brain, plasma and red blood cells of rats ( Pal and Ghosh, 2012a and Pal and Ghosh, 2012b). The authors suggested that the protective effect of ALA might be due to its bioconversion into EPA, which is known for its antioxidant properties (through enhancing the cellular antioxidant defences) (Palaniswamy et al., 2014; Shakouri Mahmoudabadi and Rahbar, 2014). However, our results show that the biological importance of ALA is not only due to its bioconversion into valuable HUFAs. Indeed, in the present study, not only EPA but also ALA enrichment protected RTL-W1 cells against MeHg and Cd toxicity while no significant bioconversion of ALA into EPA was observed in ALA-enriched cells. Therefore, EPA is unlikely to be responsible for the protective effect of ALA supplementation against $\mathrm{MeHg}$ and $\mathrm{Cd}$ toxicity. ALA itself and/or its biotransformation products (18:4n-3, 20:3n-3) would rather be at the origin of such protection.

Secondly, the protective effect of enrichment in $n$-3 PUFAs observed in the present study might be due to a higher resistance of the enriched cells to the apoptosis induced by MeHg and Cd. Indeed, EPA enrichment $(300 \mu \mathrm{M})$ has been previously shown to significantly reduce the apoptosis induced by $2.5 \mu \mathrm{M} \mathrm{MeHg}$ in the ASK cell line (Nøstbakken et al., 2012a). The authors attributed such protection to a lower synthesis of AAderived eicosanoids in the presence of EPA (Nøstbakken et al., 2012a). Indeed, contrary to EPA-derived eicosanoids, AA-derived eicosanoids were reported to increase the calcium intracellular level, which can induce apoptosis ( Rizzuto et al., 2003 and Tokuda et al., 1992). The replacement of AA by EPA in the membrane phospholipids might favour the production of EPA-derived eicosanoids over the AA-derived ones and decrease apoptosis. Since both $\mathrm{MeHg}$ and $\mathrm{Cd}$ can induce apoptosis by increasing intracellular calcium level, a decrease of AA-derived eicosanoids might partially explain the protection observed in the RTL-W1 cells supplemented with EPA in the present experiment. However, further investigations are required to test this hypothesis.

Contrary to the other $n-3$ PUFAs, DHA enrichment had no significant impact on MeHg toxicity in the present experiment. Although DHA is the most studied PUFA, the results of previous studies are contradictory. Indeed, 
in some cellular models, DHA exposure increased the damages induced by MeHg. For instance, DHA exposure exacerbated the apoptosis induced by MeHg in the ASK cell line ( Nøstbakken et al., 2012a), enhanced the production of reactive oxygen species induced by $\mathrm{MeHg}$ in the B35-neuronal cell line (Kaur et al., 2007) or increased glutathione depletion due to MeHg exposure in the C6-glial cell line (Kaur et al., 2007) and in primary cultures of cerebellar neurons (Kaur et al., 2008). However, in other models, DHA exposure did not influence GSH depletion induced by MeHg (e.g. in the B35-neuronal cell line (Kaur et al., 2007) and in primary cultures of astrocytes (Kaur et al., 2008)) or even had a protective effect. In primary cultures of cerebellar astrocytes and neurons, DHA exposure decreased the reactive oxygen species production induced by $\mathrm{MeHg}$ (Kaur et al., 2008). It is possible that the absence of protection conferred by DHA to MeHg-treated cells could reflect the occurrence of both agonistic and antagonistic actions of this PUFA. These previous results together with our study highlight the need for additional studies to clearly assess the role of DHA supplementation on cellular MeHg sensitivity, particularly in fish.

Compared to the $n$-3 PUFAs, the enrichment in $n-6$ PUFAs (LA, AA and DPA) had less impact on the cell tolerance to both MeHg and Cd as only DPA enrichment induced protection. To our knowledge, the influence of only one n-6 PUFA, AA, has previously been investigated on MeHg toxicity ( Nøstbakken et al., 2012a). In accordance with our results on RTL-W1 cells, AA enrichment did not influence MeHg uptake and apoptosis induced by MeHg in the HEK293 and ASK cell lines (Nøstbakken et al., 2012a). The protective effect of DPA against both $\mathrm{MeHg}$ and $\mathrm{Cd}$ toxicity observed in the present experiment is noteworthy and has, to our knowledge, never been demonstrated before. In particular, DPA was the only tested PUFA that protected the RTL-W1 cells against the membrane integrity damages induced by both MeHg and Cd. The cellular protection induced by DPA might thus have occurred through different mechanisms than the one induced by other tested PUFAs. DPA is a poorly studied PUFA with no clear biological role, which is rarely found in high amounts in organisms, except in some marine algae (Jiang et al., 2004) and fungi (Nakahara et al., 2003). Recent studies have shown that DPA may share similar biological functions with DHA. For instance, DPA supplementation has been recently reported to ameliorate the plasmatic lipoprotein profile of rats fed a cholesterol-rich diet in a similar extent as a DHA supplementation (Chen et al., 2012). Besides, the DPA level has also been reported to increase in brain and retina of rats in case of $n$-3 PUFA deficiency, suggesting a compensatory mechanism ( Nakahara et al., 2003). However, spatial disorders were observed in rats fed a DHA deficient diet supplemented with DPA as compared to a DHA sufficient diet, suggesting that DPA is not biologically equivalent to DHA (Lim et al., 2005). Further investigations should therefore be performed to better understand the biological functions of this n-6 PUFA and its potential protective role against MeHg and Cd toxicity.

In the present study, a higher tolerance to both $\mathrm{MeHg}$ and $\mathrm{Cd}$ was associated with a decreased phospholipid content in 20:3n-6, the precursor of AA via $\Delta 5$ desaturation. Both 20:3n-6 and AA generate eicosanoids by oxygenation. However, the eicosanoids metabolized from AA are generally considered to have proinflammatory properties whereas the eicosanoids produced from 20:3n-6 seem to have anti-inflammatory properties, as those metabolized from EPA ( Calder, 2015 and Wang et al., 2012). This contrast has increased the interest in 20:3n-6, particularly in oncology. Both anti-cancer (decreasing cell proliferation and increasing apoptosis) and pro-cancer properties (increasing tumour proliferation) were reported for 20:3n-6 in the literature (reviewed by Xu and Qian (2014)). In addition, 20:3n-6 was reported to cause sterility in C. elegans by inducing apoptosis in germ cells ( Watts and Browse, 2006). Therefore, the apoptotic potency of 20:3n-6 might partly explain the positive correlation observed, in the present study, between depletion in 20:3n-6 and increase in cell tolerance to $\mathrm{MeHg}$ and $\mathrm{Cd}$. However, further investigations, including medium supplementation with 20:3n-6, are needed to test the specific adverse effect of this PUFA on the RTL-W1 sensitivity to MeHg and Cd. 
The present study highlighted a correlation between the phospholipid composition of rainbow trout liver cells and their sensitivity to both MeHg and Cd. At present, in vivo effects of dietary lipids on sensitivity to metals are still poorly documented. In one study, fish oil dietary supplementation has been shown to protect rainbow trout against MeHg toxicity ( Olsvik et al., 2011) compared to vegetable oil dietary supplementation. The authors attributed this protective impact to the high level of long chain $n$-3 HUFAs in fish oil. However, oils also contain other valuable components, such as vitamins and phenolic compounds, the concentration of which largely depends on the oil type and brand. In vivo experiments using diets differing only in their lipid composition are therefore still needed to validate the correlations observed in the present in vitro study.

In conclusion, the present study highlighted the interest and the pertinence of the RTL-W1 cell model to investigate the biological roles of specific PUFAs separately. We used this model to show that the nature of the PUFA supply modulates fish liver cell tolerance to metallic compounds. In particular, ALA, EPA and DPA enrichment significantly protected the cells against both MeHg and Cd while DHA enrichment significantly protected the cells against Cd but not MeHg. In addition, AA and LA enrichment had no impact on both MeHg and Cd toxicity. Besides, ALA was found to have a protective effect by itself and/or through its direct biotransformation products (18:4n-3, 20:3n-3), independently of its further bioconversion into EPA or DHA. Taken together, these results indicate that the nature of the PUFA supplied is an important factor influencing the tolerance of fish liver cells to both MeHg and Cd toxicity. Further investigations should focus on the mechanisms behind the observed interactions. In addition, in vivo experiments with diets differing only by their fatty acid concentrations are required to confirm the results obtained in vitro with the RTL-W1 cell line.

\section{Acknowledgements}

The research leading to these results has received funding from Belspo for the IAP AQUASTRESS (P7/31), from the European Union Seventh Framework Programme (FP7/2007-2013) under grant agreement PIEF-GA2012-332049 for FISHSTRESS project and from the Fonds de la Recherche Scientifique (FNRS) (Aline Ferain is a F.R.I.A. Grant Holder of the FNRS). The authors aknowledge Alix Zuyderhoff for her contribution to this work.

\section{$\underline{\text { References }}$}

Amamou, F., Nemmiche, S., Meziane, R.K., Didi, A., Yazit, S.M., Chabane-Sari, D., 2015. Protective effect of olive oil and colocynth oil against cadmium-induced oxidative stress in the liver of Wistar rats. Food Chem. Toxicol. 78, 177-184.

Arts, M.T., Kohler, C.C., 2009. Health and condition in fish: the influence of lipids on membrane competency and immune response. Lipids Aquat. Ecosyst., 237-256.

Bell, J.G., McEvoy, J., Tocher, D.R., McGhee, F., Campbell, P.J., Sargent, J.R., 2001. Replacement of fish oil with rapeseed oil in diets of atlantic salmon (Salmo salar) affects tissue lipid compositions and hepatocyte fatty acid metabolism. J. Nutr. 131, 1535-1543.

Bell, J.G., Henderson, R.J., Tocher, D.R., Sargent, J.R., 2004. Replacement of dietary fish oil with increasing levels of linseed oil: modification of flesh fatty acid compositions in atlantic salmon (Salmo salar) using a fish oil finishing diet. Lipids 39, 223-232.

Bell, J.G., Strachan, F., Good, J.E., Tocher, D.R., 2006. Effect of dietary echium oil on growth, fatty acid composition and metabolism: gill prostaglandin production and macrophage activity in Atlantic cod (Gadus morhua L.). Aquacult. Res. 37, 606-617.

Best, C.A., Laposata, M., Poios, V.G., Szczepiorkowski, Z.M., 2006. Method to assess fatty acid ethyl ester 
binding to albumin. Alcohol 41, 240-246.

Bligh, E.G., Dyer, W.J., 1959. A rapid method of total lipid extraction and purification. Can. J. Biochem. Physiol. 37, 911-917.

Boening, D.W., 2000. Ecological effects, transport, and fate of mercury. Gen. Rev. Chemosphere 40, 13351351.

Buzzi, M., Henderson, R.J., Sargent, J.R., 1996. The desaturation and elongation of linolenic acid and eicosapentaenoic acid by hepatocytes and liver microsomes from rainbow trout (Oncorhynchus mykiss) fed diets containing fish oil or olive oil. Biochim. et Biophys. Acta - Lipids Lipid Metab. 1299, 235-244.

Caballero, M.J., Obach, A., Rosenlund, G., Montero, D., Gisvold, M., Izquierdo, M.S., 2002. Impact of different dietary lipid sources on growth, lipid digestibility, tissue fatty acid composition and histology of rainbow trout, oncorhynchus mykiss. Aquaculture 214, 253-271.

Calder, P.C., 2015. Marine omega-3 fatty acids and inflammatory processes: effects, mechanisms and clinical relevance. Biochim. et Biophys. Acta - Lipids Lipid Metab. 1851, 469-484.

Cambier, S., Bénard, G., Mesmer-Dudons, N., Gonzalez, P., Rossignol, R., Brèthes, D., Bourdineaud, J.P., 2009. At environmental doses: dietary methylmercury inhibits mitochondrial energy metabolism in skeletal muscles of the zebra fish (Danio rerio). Int. J. Biochem. Cell Biol. 41, 791-799.

Casalino, E., Calzaretti, G., Sblano, C., Landriscina, C., 2002. Molecular inhibitory mechanisms of antioxidant enzymes in rat liver and kidney by cadmium. Toxicology 179, 37-50.

Catalá, A., 2012. Lipid peroxidation modifies the picture of membranes from the fluid Mosaic Model to the lipid Whisker Model. Biochimie 94, 101-109.

Chen, J., Jiang, Y., Liang, Y., Tian, X., Peng, C., Ma, K.Y., Liu, J., Huang, Y., Chen, Z.Y., 2012. DPA n-3, DPA n-6 and DHA improve lipoprotein profiles and aortic function in hamsters fed a high cholesterol diet.

Atherosclerosis 221, 397-404.

Dayeh, V.R., Schirmer, K., Bols, N.C., 2002. Applying whole-water samples directly to fish cell cultures in order to evaluate the toxicity of industrial effluent. Water Res. 36, 3727-3738.

Dayeh, V.R., Lynn, D.H., Bols, N.C., 2005. Cytotoxicity of metals common in mining effluent to rainbow trout cell lines and to the ciliated protozoan, Tetrahymena thermophila. Toxicol. In Vitro 19, 399-410.

Dudgeon, D., Arthington, A.H., Gessner, M.O., Kawabata, Z.I., Knowler, D.J., Lévêque, C., Naiman, R.J., Prieur-Richard, A.H., Soto, D., Stiassny, M.L.J., Sullivan, C.A., 2006. Freshwater biodiversity Importance, threats, status and conservation challenges. Biol. Rev. Camb. Philos. Soc. 81, 163-182.

Dudgeon, D., 2010. Prospects for sustaining freshwater biodiversity in the 21 st century: linking ecosystem structure and function. Curr. Opin. Environ. Sustainability 2, 422-430.

Farina, M., Rocha, J.B.T., Aschner, M., 2011. Mechanisms of methylmercury-induced neurotoxicity: evidence from experimental studies. Life Sci. 89, 555-563.

Fonseca-Madrigal, J., Karalazos, V., Campbell, P.J., Bell, J.G., Tocher, D.R., 2005. Influence of dietary palm oil on growth, tissue fatty acid compositions, and fatty acid metabolism in liver and intestine in rainbow trout (Oncorhynchus mykiss). Aquacult. Nutr. 11, 241-250.

Gregory, M., King, H., Bain, P., Gibson, R., Tocher, D., Schuller, K., 2011. Development of a fish cell culture model to investigate the impact of fish oil replacement on lipid peroxidation. Lipids 46, 753-764.

Grotto, D., Vicentini, J., Friedmann Angeli, J.P., Francisco Latorraca, E., Pontes Monteiro, P.A., Mazzaron Barcelos, G.R., Somacal, S., Emanuelli, T., Barbosa, F., 2011. Evaluation of protective effects of fish oil against oxidative damage in rats exposed to methylmercury. Ecotoxicol. Environ. Saf. 74, 487-493. 
Hagopian, K., Weber, K.L., Hwee, D.T., van Eenennaam, A.L., López-Lluch, G., Villalba, J.M., Burón, I., Navas, P., German, J.B., Watkins, S.M., Chen, Y., Wei, A., McDonald, R.B., Ramsey, J.J., 2010. Complex iassociated hydrogen peroxide production is decreased and electron transport chain enzyme activities are altered in n-3 enriched fat-1 mice. PLoS One 5, 1-11.

Hall, B.D., Bodaly, R.A., Fudge, R.J.P., Rudd, J.W.M., Rosenberg, D.M., 1997. Food as the dominant pathway of methylmercury uptake by fish. Water. Air. Soil Pollut. 100, 13-24.

Harada, M., 1995. Minamata disease - methylmercury poisoning in japan caused by environmental pollution. Crit. Rev. Toxicol. 25, 1-24.

Heggland, I., Kaur, P., Syversen, T., 2009. Uptake and efflux of methylmercury in vitro: comparison of transport mechanisms in C6, B35 and RBE4 cells. Toxicol. In Vitro 23, 1020-1027.

Holmstrup, M., Bindesbøl, A.M., Oostingh, G.J., Duschl, A., Scheil, V., Köhler, H.R., Loureiro, S., Soares, A.M.V.M., Ferreira, A.L.G., Kienle, C., Gerhardt, A., Laskowski, R., Kramarz, P.E., Bayley, M., Svendsen, C., Spurgeon, D.J., 2010. Interactions between effects of environmental chemicals and natural stressors. Rev. Sci. Total Environ. 408, 3746-3762.

Jayashankar, S., Glover, C.N., Folven, K.I., Brattelid, T., Hogstrand, C., Lundebye, A.K., 2012. Cerebral gene expression and neurobehavioural responses in mice pups exposed to methylmercury and docosahexaenoic acid through the maternal diet. Environ. Toxicol. Pharmacol. 33, 26-38.

Jiang, Y., Fan, K.W., Wong, R.T.Y., Chen, F., 2004. Fatty acid composition and squalene content of the marine microalga schizochytrium mangrovei. J. Agric. Food Chem. 52, 1196-1200.

Jin, X., Lok, E., Bondy, G., Caldwell, D., Mueller, R., Kapal, K., Armstrong, C., Taylor, M., Kubow, S., Mehta, R., Chan, H.M., 2007. Modulating effects of dietary fats on methylmercury toxicity and distribution in rats. Toxicology 230, 22-44.

Jin, X., Chan, H.M., Lok, E., Kapal, K., Taylor, M., Kubow, S., Mehta, R., 2008. Dietary fats modulate methylmercury-mediated systemic oxidative stress and oxidative DNA damage in rats. Food Chem. Toxicol. 46, 1706-1720.

Kaur, P., Schulz, K., Aschner, M., Syversen, T., 2007. Role of docosahexaenoic acid in modulating methylmercury-induced neurotoxicity. Toxicol. Sci. 100, 423-432.

Kaur, P., Heggland, I., Aschner, M., Syversen, T., 2008. Docosahexaenoic acid may act as a neuroprotector for methylmercury-induced neurotoxicity in primary neural cell cultures. Neurotoxicology 29, 978-987.

Kidd, K., Batchelar, K., 2011. Mercury. Fish Physiol., 237-295.

Klinck, J.S., Wood, C.M., 2011. In vitro characterization of cadmium transport along the gastro-intestinal tract of freshwater rainbow trout (Oncorhynchus mykiss). Aquat. Toxicol. 102, 58-72.

Lavoie, R.A., Jardine, T.D., Chumchal, M.M., Kidd, K.A., Campbell, L.M., 2013. Biomagnification of mercury in aquatic food webs: a worldwide meta-analysis. Environ. Sci. Technol. 47, 13385-13394.

Lee, L.E.J., Clemons, J.H., Bechtel, D.G., Caldwell, S.J., Han, K.B., Pasitschniak-Arts, M., Mosser, D.D., Bols, N.C., 1993. Development and characterization of a rainbow trout liver cell line expressing cytochrome P450dependent monooxygenase activity. Cell Biol. Toxicol. 9, 279-294.

Lim, S.Y., Hoshiba, J., Salem Jr, N., 2005. An extraordinary degree of structural specificity is required in neural phospholipids for optimal brain function: n-6 docosapentaenoic acid substitution for docosahexaenoic acid leads to a loss in spatial task performance. J. Neurochem. 95, 848-857.

Matović, V., Buha, A., Dukić-Ćosić, D., Bulat, Z., 2015. Insight into the oxidative stress induced by lead and/or cadmium in blood liver and kidneys. Food Chem. Toxicol. 78, 130-140. 
McGeer, J.C., Niyogi, S., Scott Smith, D., 2011. Cadmium. Fish Physiology, 125-184.

Mourente, G., Bell, J.G., 2006. Partial replacement of dietary fish oil with blends of vegetable oils (rapeseed: linseed and palm oils) in diets for European sea bass (Dicentrarchus labrax L.) over a long term growth study: effects on muscle and liver fatty acid composition and effectiveness of a fish oil finishing diet. Comp.

Biochem. Physio.- B Biochem. Mol. Biol. 145, 389-399.

Mourente, G., Tocher, D.R., 1998. The in vivo incorporation and metabolism of [1-14C] linolenate (18:3n-3) in liver, brain and eyes of juveniles of rainbow trout oncorhynchus mykiss L and gilthead sea bream Sparus aurata L. Fish. Physiol. Biochem. 18, 149-165.

Nøstbakken, O.J., Bredal, I.L., Olsvik, P.A., Huang, T.S., Torstensen, B.E., 2012a. Effect of marine omega 3 fatty acids on methylmercury-induced toxicity in fish and mammalian cells in vitro. J. Biomed. Biotechnol., 2012.

Nøstbakken, O.J., Goksøyr, A., Martin, S.A.M., Cash, P., Torstensen, B.E., 2012b. Marine n-3 fatty acids alter the proteomic response to methylmercury in Atlantic salmon kidney (ASK) cells. Aquatic toxicology 106-107, $65-75$.

Nakahara, T., Yokochi, T., Kumon, Y., Yamaoka, M., 2003. A Labyrinthulid Isolate Producing Docosapentaenoic Acid (DPA, 22: 5n-6) and Physiological Functions of DPA Reported to Date, Essential Fatty Acids and Eicosanoids: Invited Papers from the Fifth International Congress. The American Oil Chemists Society, p. 24.

Olsvik, P.A., Amlund, H., Torstensen, B.E., 2011. Dietary lipids modulate methylmercury toxicity in Atlantic salmon. Food Chem. Toxicol. 49, 3258-3271.

Pal, M., Ghosh, M., 2012a. Prophylactic effect of alpha-linolenic acid and alpha-eleostearic acid against MeHg induced oxidative stress, DNA damage and structural changes in RBC membrane. Food Chem. Toxicol. 50, 2811-2818.

Pal, M., Ghosh, M., 2012b. Studies on comparative efficacy of alpha-linolenic acid and alpha-eleostearic acid on prevention of organic mercury-induced oxidative stress in kidney and liver of rat. Food Chem. Toxicol. 50, 1066-1072.

Palaniswamy, K.S., Vishwanadha, V.P., Ramalingam Singaravelu, S., 2014. Fish oil rich in eicosapentaenoic acid protects against oxidative stress-related renal dysfunction induced by TCDD in Wistar rats. Cell Stress Chaperones 19, 409-419.

Pan, J., Plant, J.A., Voulvoulis, N., Oates, C.J., Ihlenfeld, C., 2010. Cadmium levels in Europe: implications for human health. Environ. Geochem. Health 32, 1-12.

Peters, K., Bundschuh, M., Schäfer, R.B., 2013. Review on the effects of toxicants on freshwater ecosystem functions. Environ. Pollut. 180, 324-329.

Petropoulos, I.K., Thompson, K.D., Morgan, A., Dick, J.R., Tocher, D.R., Bell, J.G., 2009. Effects of substitution of dietary fish oil with a blend of vegetable oils on liver and peripheral blood leucocyte fatty acid composition, plasma prostaglandin E2 and immune parameters in three strains of Atlantic salmon (Salmo salar). Aquacult. Nutr. 15, 596-607. 177 (2016) 171-181

Remø, S.C., Olsvik, P.A., Torstensen, B.E., Amlund, H., Breck, O., Waagbø, R., 2011. Susceptibility of Atlantic salmon lenses to hydrogen peroxide oxidation ex vivo after being fed diets with vegetable oil and methylmercury. Exp. Eye Res. 92, 414-424.

Rizzuto, R., Pinton, P., Ferrari, D., Chami, M., Szabadkai, G., Magalhães, P.J., Di Virgilio, F., Pozzan, T., 2003. Calcium and apoptosis: facts and hypotheses. Oncogene 22, 8619-8627.

Rolfhus, K.R., Hall, B.D., Monson, B.A., Paterson, M.J., Jeremiason, J.D., 2011. Assessment of mercury 
bioaccumulation within the pelagic food web of lakes in the western Great Lakes region. Ecotoxicology 20, 1520-1529.

Rytuba, J.J., 2003. Mercury from mineral deposits and potential environmental impact. Environ. Geol. 43, 326338.

Schabenberger, O., Tharp, B.E., Kells, J.J., Penner, D., 1999. Statistical tests for hormesis and effective dosages in herbicide dose response contribution of the michigan state univ. Dep. Crop Soil Sci. Agron. J. 91, 713-721.

Scheffczyk, A., Frankenbach, S., Jänsch, S., Römbke, J., 2014. Comparison of the effects of zinc nitratetetrahydrate and tributyltin-oxide on the reproduction and avoidance behavior of the earthworm Eisenia andrei in laboratory tests using nine soils. Appl. Soil Ecol. 83, 253-257.

Schneider, A.C., Beguin, P., Bourez, S., Perfield, J.W., Mignolet, E., Debier, C., Schneider, Y.J., Larondelle, Y., 2012. Conversion of t11t13 CLA into C9t11 CLA in CACO-2 cells and inhibition by sterculic oil. PLoS One 7.

Sebastian, A., Prasad, M.N.V., 2014. Cadmium minimization in rice: a review. Agron. Sustainable Dev. 34, 155-173.

Sevcikova, M., Modra, H., Slaninova, A., Svobodova, Z., 2011. Metals as a cause of oxidative stress in fish: a review. Vet. Med. (Praha). 56, 537-546.

Shakouri Mahmoudabadi, M.M., Rahbar, A.R., 2014. Effect of EPA and vitamin C on superoxide dismutase, glutathione peroxidase, total antioxidant capacity and malondialdehyde in type 2 diabetic patients. Oman. Med. J. 29, 39-45.

Snyder, R.J., Schregel, W.D., Wei, Y., 2012. Effects of thermal acclimation on tissue fatty acid composition of freshwater alewives (Alosa pseudoharengus). Fish. Physiol. Biochem. 38, 363-373.

Tillman, T.S., Cascio, M., 2003. Effects of membrane lipids on ion channel structure and function. Cell Biochem. Biophys. 38, 161-190.

Tocher, D.R., Dick, J.R., 1990. Polyunsaturated fatty acid metabolism in cultured fish cells: incorporation and metabolism of (n-3) and (n-6) series acids by Atlantic salmon (Salmo salar) cells. Fish. Physiol. Biochem. 8, 311-319.

Tocher, D.R., Sargen, J.R., Frerichs, G.N., 1988. The fatty acid compositions of established fish cell lines after long-term culture in mammalian sera. Fish. Physiol. Biochem. 5, 219-227.

Tocher, D.R., 1990. Incorporation and metabolism of (n-3) and (n-6) polyunsaturated fatty acids in phospholipid classes in cultured rainbow trout (Salmo gairdneri) cells. Fish. Physiol. Biochem. 8, 239-249.

Tocher, D.R., 2003. Metabolism and functions of lipids and fatty acids in teleost fish. Rev. Fish. Sci. 11, 107184.

Tokuda, H., Miwa, M., Oiso, Y., Kozawa, O., 1992. Autoregulation of prostaglandin E2-induced Ca2+ influx in osteoblast-like cells: inhibition by self-induced activation of protein kinase C. Cell. Signal. 4, 261-266.

Van Straalen, N.M., 2003. Ecotoxicology becomes stress ecology. Environ. Sci. Technol. 37, 324A-330A.

Wang, Y., Fang, J., Leonard, S.S., Rao, K.M.K., 2004. Cadmium inhibits the electron transfer chain and induces reactive oxygen species. Free Radic. Biol. Med. 36, 1434-1443.

Wang, X., Lin, H., Gu, Y., 2012. Multiple roles of dihomo-gamma-linolenic acid against proliferation diseases. Lipids Health Dis., 11.

Wang, J., Zhang, H., Zhang, T., Zhang, R., Liu, R., Chen, Y., 2015. Molecular mechanism on cadmium-induced activity changes of catalase and superoxide dismutase. Int. J. Biol. Macromol. 77, 59-67.

Watts, J.L., Browse, J., 2006. Dietary manipulation implicates lipid signaling in the regulation of germ cell 
maintenance in C elegans. Dev. Biol. 292, 381-392.

Wijekoon, M.P.A., Parrish, C.C., Mansour, A., 2014. Effect of dietary substitution of fish oil with flaxseed or sunflower oil on muscle fatty acid composition in juvenile steelhead trout (Oncorhynchus mykiss) reared at varying temperatures. Aquaculture 433, 74-81.

Xu, Y., Qian, S., 2014. Anti-cancer activities of omega-6 polyunsaturated fatty acids. Biomed. J. 37, 112-119.

\section{Supplementary data}

SUPPLEMENTARY TABLE 1 - Fatty acid profile of the RTL-W1 cells neutral lipids after a 7 daysupplementation with $50 \mu \mathrm{M}$ PUFA ( $\mu \mathrm{mol} / \mathrm{g}$ proteins). Data are expressed as means \pm standard error of mean ( $\mathrm{n}=3$, 4 or 7). Stars indicate significant differences as compared to the control (Wilcoxon Rank Sum Test, total alpha $=0.05, \mathrm{p}<0.05$ ). Abbreviation used: ALA, alpha-linolenic acid; EPA, eicosapentaenoic acid; DHA, docosahexaenoic acid; LA, linoleic acid; AA, arachidonic acid; DPA, docosapentaenoic acid; SFA, saturated fatty acid; MUFA, monounsaturated fatty acid; PUFA, polyunsaturated fatty acid.

\begin{tabular}{|c|c|c|c|c|c|c|c|c|c|c|c|c|c|c|c|c|c|c|c|c|c|}
\hline \multirow{2}{*}{$\begin{array}{l}\text { Fatty acid } \\
16: 0\end{array}$} & \multicolumn{3}{|c|}{ Control } & \multicolumn{3}{|c|}{ ALA } & \multicolumn{3}{|c|}{ EPA } & \multicolumn{3}{|c|}{$\mathrm{DHA}$} & \multicolumn{3}{|c|}{ LA } & \multicolumn{3}{|c|}{ AA } & \multicolumn{3}{|c|}{ DPA } \\
\hline & 30.0 & \pm & 5.3 & 19.9 & \pm & 1.7 & 28.7 & \pm & 1.0 & 19.5 & \pm & 1.8 & 41.4 & \pm & 21.6 & 28.9 & \pm & 1.3 & 36.5 & \pm & 6.8 \\
\hline $18: 0$ & 25.6 & \pm & 6.8 & 16.8 & \pm & 1.4 & 24.5 & \pm & 2.1 & 15.8 & \pm & 1.7 & 57.1 & \pm & 34.4 & 24.7 & \pm & 4.6 & 33.4 & \pm & 11.4 \\
\hline Total SFA & 55.6 & \pm & 11.7 & 36.7 & \pm & 3.1 & 53.8 & \pm & 2.7 & 35.3 & \pm & 3.5 & 98.5 & \pm & 56.1 & 53.5 & \pm & 4.7 & 69.9 & \pm & 17.1 \\
\hline $16: 1 n-7$ & 0.0 & \pm & 0.0 & 0.0 & \pm & 0.0 & 0.0 & \pm & 0.0 & 0.0 & \pm & 0.0 & 0.0 & \pm & 0.0 & 0.3 & \pm & 0.3 & 0.0 & \pm & 0.0 \\
\hline Total MUFA & 0.0 & \pm & 0.0 & 0.0 & \pm & 0.0 & 0.0 & \pm & 0.0 & 0.0 & \pm & 0.0 & 0.0 & \pm & 0.0 & 0.3 & \pm & 0.3 & 0.0 & \pm & 0.0 \\
\hline ALA $18: 3 n-3$ & 0.0 & \pm & 0.0 & 16.5 & \pm & 2.9 * & 0.0 & \pm & 0.0 & 0.0 & \pm & 0.0 & 0.0 & \pm & 0.0 & 0.0 & \pm & 0.0 & 0.0 & \pm & 0.0 \\
\hline EPA $20: 5 n-3$ & 0.0 & \pm & 0.0 & 0.0 & \pm & 0.0 & 6.4 & \pm & 3.3 & 0.0 & \pm & 0.0 & 0.0 & \pm & 0.0 & 0.0 & \pm & 0.0 & 0.0 & \pm & 0.0 \\
\hline $22: 5 n-3$ & 0.0 & \pm & 0.0 & 0.0 & \pm & 0.0 & 0.0 & \pm & 0.0 & 0.0 & \pm & 0.0 & 0.0 & \pm & 0.0 & 0.0 & \pm & 0.0 & 0.7 & \pm & 0.7 \\
\hline DHA $22: 6 n-3$ & 0.0 & \pm & 0.0 & 0.0 & \pm & 0.0 & 0.0 & \pm & 0.0 & 19.3 & \pm & 3.3 & 0.0 & \pm & 0.0 & 0.0 & \pm & 0.0 & 1.0 & \pm & 1.0 \\
\hline Total n-3 PUFA & 0.0 & \pm & 0.0 & 16.5 & \pm & 2.9 & 6.4 & \pm & 3.3 & 19.3 & \pm & 3.3 & 0.0 & \pm & 0.0 & 0.0 & \pm & 0.0 & 1.7 & \pm & 1.7 \\
\hline LA $18: 2 n-6$ & 0.0 & \pm & 0.0 & 0.0 & \pm & 0.0 & 0.0 & \pm & 0.0 & 0.0 & \pm & 0.0 & 25.4 & \pm & 7.9 & 0.0 & \pm & 0.0 & 0.0 & \pm & 0.0 \\
\hline AA $20: 4 n-6$ & 0.0 & \pm & 0.0 & 0.0 & \pm & 0.0 & 0.0 & \pm & 0.0 & 0.0 & \pm & 0.0 & 0.0 & \pm & 0.0 & 14.2 & \pm & 5.8 & 0.0 & \pm & 0.0 \\
\hline DPA $22: 5 n-6$ & 0.0 & \pm & 0.0 & 0.0 & \pm & 0.0 & 0.0 & \pm & 0.0 & 0.0 & \pm & 0.0 & 0.0 & \pm & 0.0 & 0.0 & \pm & 0.0 & 114.2 & \pm & 67.2 \\
\hline Total n-6 PUFA & 0.0 & \pm & 0.0 & 0.0 & \pm & 0.0 & 0.0 & \pm & 0.0 & 0.0 & \pm & 0.0 & 25.4 & \pm & 7.9 & 14.2 & \pm & 5.8 & 114.2 & \pm & 67.2 \\
\hline Total PUFA & 0.0 & \pm & 0.0 & 16.5 & \pm & 2.9 & 6.4 & \pm & 3.3 & 19.3 & \pm & 3.3 & 25.4 & \pm & 7.9 & 14.2 & \pm & 5.8 & 115.9 & \pm & 68.8 \\
\hline Total & 55.6 & \pm & 11.7 & 53.2 & \pm & 6.0 & 60.2 & \pm & 4.7 & 54.6 & \pm & 6.5 & 123.9 & \pm & 58.6 & 68.0 & \pm & $\begin{array}{l}4.5 \\
0.0\end{array}$ & 185.8 & \pm & 63.9 \\
\hline n-3/n-6 ratio & & & & & & & & & & & & & 0.00 & \pm & 0.00 & 0.00 & \pm & 0 & 0.01 & \pm & 0.01 \\
\hline
\end{tabular}

SUPPLEMENTARY TABLE 2 - Fatty acid profile of the RTL-W1 cells free fatty acids after a 7 daysupplementation with $50 \mu \mathrm{M}$ PUFA ( $\mu \mathrm{mol} / \mathrm{g}$ proteins). Data are expressed as means \pm standard error of mean ( $\mathrm{n}=3,4$ or 7). Abbreviation used: ALA, alpha-linolenic acid; EPA, eicosapentaenoic acid; DHA, docosahexaenoic acid; LA, linoleic acid; AA, arachidonic acid; DPA, docosapentaenoic acid; SFA, saturated fatty acid; MUFA, monounsaturated fatty acid; PUFA, polyunsaturated fatty acid.

\begin{tabular}{|c|c|c|c|c|c|c|c|c|c|c|c|c|c|c|c|c|c|c|c|c|c|}
\hline \multirow{2}{*}{$\begin{array}{l}\text { Fatty acid } \\
16: 0\end{array}$} & \multicolumn{3}{|c|}{ Control } & \multicolumn{3}{|c|}{ ALA } & \multicolumn{3}{|c|}{ EPA } & \multicolumn{3}{|c|}{$\mathrm{DHA}$} & \multicolumn{3}{|c|}{ LA } & \multicolumn{3}{|c|}{ AA } & \multicolumn{3}{|c|}{ DPA } \\
\hline & 130.6 & \pm & 12.1 & 121.0 & \pm & 9.2 & 155.9 & \pm & 24.9 & 105.2 & \pm & 2.6 & 87.6 & \pm & 24.1 & 127.3 & \pm & 33.2 & 134.2 & \pm & 21.3 \\
\hline $18: 0$ & 95.3 & \pm & 8.2 & 87.3 & \pm & 6.6 & 112.0 & \pm & 17.1 & 76.6 & \pm & 2.5 & 65.0 & \pm & 16.1 & 93.0 & \pm & 21.8 & 102.3 & \pm & 13.8 \\
\hline Total SFA & 225.9 & \pm & 20.2 & 208.4 & \pm & 15.8 & 267.9 & \pm & 42.0 & 181.8 & \pm & 5.0 & 152.6 & \pm & 40.1 & 220.3 & \pm & 55.0 & 236.5 & \pm & 34.8 \\
\hline Total MUFA & 0.0 & \pm & 0.0 & 0.0 & \pm & 0.0 & 0.0 & \pm & 0.0 & 0.0 & \pm & 0.0 & 0.0 & \pm & 0.0 & 0.0 & \pm & 0.0 & 0.0 & \pm & 0.0 \\
\hline ALA $18: 3 n-3$ & 0.0 & \pm & 0.0 & 3.7 & \pm & 3.7 & 0.0 & \pm & 0.0 & 0.0 & \pm & 0.0 & 0.0 & \pm & 0.0 & 0.0 & \pm & 0.0 & 0.0 & \pm & 0.0 \\
\hline EPA $20: 5 n-3$ & 0.0 & \pm & 0.0 & 0.0 & \pm & 0.0 & 4.6 & \pm & 2.3 & 0.0 & \pm & 0.0 & 0.0 & \pm & 0.0 & 0.0 & \pm & 0.0 & 0.0 & \pm & 0.0 \\
\hline DHA $22: 6 n-3$ & 0.0 & \pm & 0.0 & 0.0 & \pm & 0.0 & 0.0 & \pm & 0.0 & 2.6 & \pm & 2.6 & 0.0 & \pm & 0.0 & 0.0 & \pm & 0.0 & 0.0 & \pm & 0.0 \\
\hline Total $n-3$ PUFA & 0.0 & \pm & 0.0 & 3.7 & \pm & 3.7 & 4.6 & \pm & 2.3 & 2.6 & \pm & 2.6 & 0.0 & \pm & 0.0 & 0.0 & \pm & 0.0 & 0.0 & \pm & 0.0 \\
\hline LA $18: 2 n-6$ & 0.0 & \pm & 0.0 & 0.0 & \pm & 0.0 & 0.0 & \pm & 0.0 & 0.0 & \pm & 0.0 & 5.3 & \pm & 2.7 & 0.0 & \pm & 0.0 & 0.0 & \pm & 0.0 \\
\hline AA $20: 4 n-6$ & 0.0 & \pm & 0.0 & 0.0 & \pm & 0.0 & 0.0 & \pm & 0.0 & 0.0 & \pm & 0.0 & 0.0 & \pm & 0.0 & 5.4 & \pm & 3.1 & 0.0 & \pm & 0.0 \\
\hline DPA $22: 5 n-6$ & 0.0 & \pm & 0.0 & 0.0 & \pm & 0.0 & 0.0 & \pm & 0.0 & 0.0 & \pm & 0.0 & 0.0 & \pm & 0.0 & 0.0 & \pm & 0.0 & 2.9 & \pm & 2.9 \\
\hline Total $n-6$ PUFA & 0.0 & \pm & 0.0 & 0.0 & \pm & 0.0 & 0.0 & \pm & 0.0 & 0.0 & \pm & 0.0 & 5.3 & \pm & 2.7 & 5.4 & \pm & 3.1 & 2.9 & \pm & 2.9 \\
\hline Total PUFA & 0.0 & \pm & 0.0 & 3.7 & \pm & 3.7 & 4.6 & \pm & 2.3 & 2.6 & \pm & 2.6 & 5.3 & \pm & 2.7 & 5.4 & \pm & 3.1 & 2.9 & \pm & 2.9 \\
\hline Total & 225.9 & \pm & 20.2 & 212.1 & \pm & 18.5 & 272.5 & \pm & 40.1 & 184.4 & \pm & 7.6 & 157.9 & \pm & 42.2 & 225.6 & \pm & 54.6 & 239.4 & \pm & 34.5 \\
\hline$n-3 / n-6$ ratio & & & & & & & & & & & & & 0.00 & \pm & 0.00 & 0.00 & \pm & 0.00 & 0.00 & \pm & 0.00 \\
\hline
\end{tabular}


SUPPLEMENTARY TABLE 3 - EC50s of MeHg and Cd for membrane integrity (as measured by the 5CFDA,AM assay) in RTL-W1cells enriched in different fatty acids. The EC50s and their confidence interval (at 98.3\%) were obtained by estimating the parameters of the LogLogistic or Brain \& Cousens models, which were fitted to the data from the independent repetitions ( $n=3$ or 4). Abbreviation used: MeHg, methylmercury; EC50, median effect concentration; Cd, cadmium; PUFA, polyunsaturated fatty acid; ALA, alpha-linolenic acid; EPA, eicosapentaenoic acid; DHA, docosahexaenoic acid; LA, linoleic acid; AA, arachidonic acid; DPA, docosapentaenoic acid.

\begin{tabular}{|c|c|c|c|c|c|c|}
\hline \multirow[b]{2}{*}{$\begin{array}{c}\text { PUFA } \\
\text { enrichment }\end{array}$} & \multicolumn{3}{|c|}{$\mathrm{MeHg}$ EC50 } & \multicolumn{3}{|c|}{ Cd EC50 } \\
\hline & $\begin{array}{l}\text { Estimation } \\
\qquad(\mu \mathrm{M})\end{array}$ & $\begin{array}{c}\text { Confidence } \\
\text { interval }(\mu \mathrm{M})\end{array}$ & $\begin{array}{l}\text { Fold change } \\
\text { (compared to } \\
\text { the control) }\end{array}$ & $\begin{array}{l}\text { Estimation } \\
\qquad(\mu \mathrm{M})\end{array}$ & $\begin{array}{c}\text { Confidence } \\
\text { interval }(\mu \mathrm{M})\end{array}$ & $\begin{array}{l}\text { Fold change } \\
\text { (compared to } \\
\text { the control) }\end{array}$ \\
\hline $\begin{array}{c}\text { Control } n- \\
3\end{array}$ & 6.37 & [5.09 - 7.93] & 1.0 & 205.5 & [173.4 - 243.0] & 1.0 \\
\hline ALA & 7.23 & [5.67 - 8.87] & 1.1 & 190.0 & [170.4 - 211.5] & 0.9 \\
\hline EPA & 5.94 & [4.62 - 7.49] & 0.9 & 191.8 & [161.3 - 228.3] & 0.9 \\
\hline DHA & 5.23 & [3.91 - 6.92] & 0.8 & 205.2 & [179.9 - 233.7] & 1.0 \\
\hline $\begin{array}{c}\text { Control } n- \\
6\end{array}$ & 3.80 & {$[3.07-4.66]$} & 1.0 & 76.5 & [68.2 - 85.4] & 1.0 \\
\hline LA & 4.87 & [3.35 - 6.90] & 1.3 & 85.0 & [60.1 - 114.0] & 1.1 \\
\hline AA & 5.31 & [3.64 - 7.47] & 1.4 & 80.3 & [64.2 - 98.5] & 1.0 \\
\hline DPA & 7.52 & [5.05 - 10.79] & 2.0 & 113.2 & [92.5 - 137.3] & 1.5 \\
\hline
\end{tabular}


SUPPLEMENTARY TABLE 4 - Parameters of the LogLogistic and Brain \& Cousens models fitted to the cytotoxicity data. Abbreviation used: PUFA, polyunsaturated fatty acid; EC50, median effect concentration; MeHg, methylmercury; Cd, cadmium; ALA, alpha-linolenic acid; EPA, eicosapentaenoic acid; DHA, docosahexaenoic acid; LA linoleic acid; AA, arachidonic acid; DPA, docosapentaenoic acid.

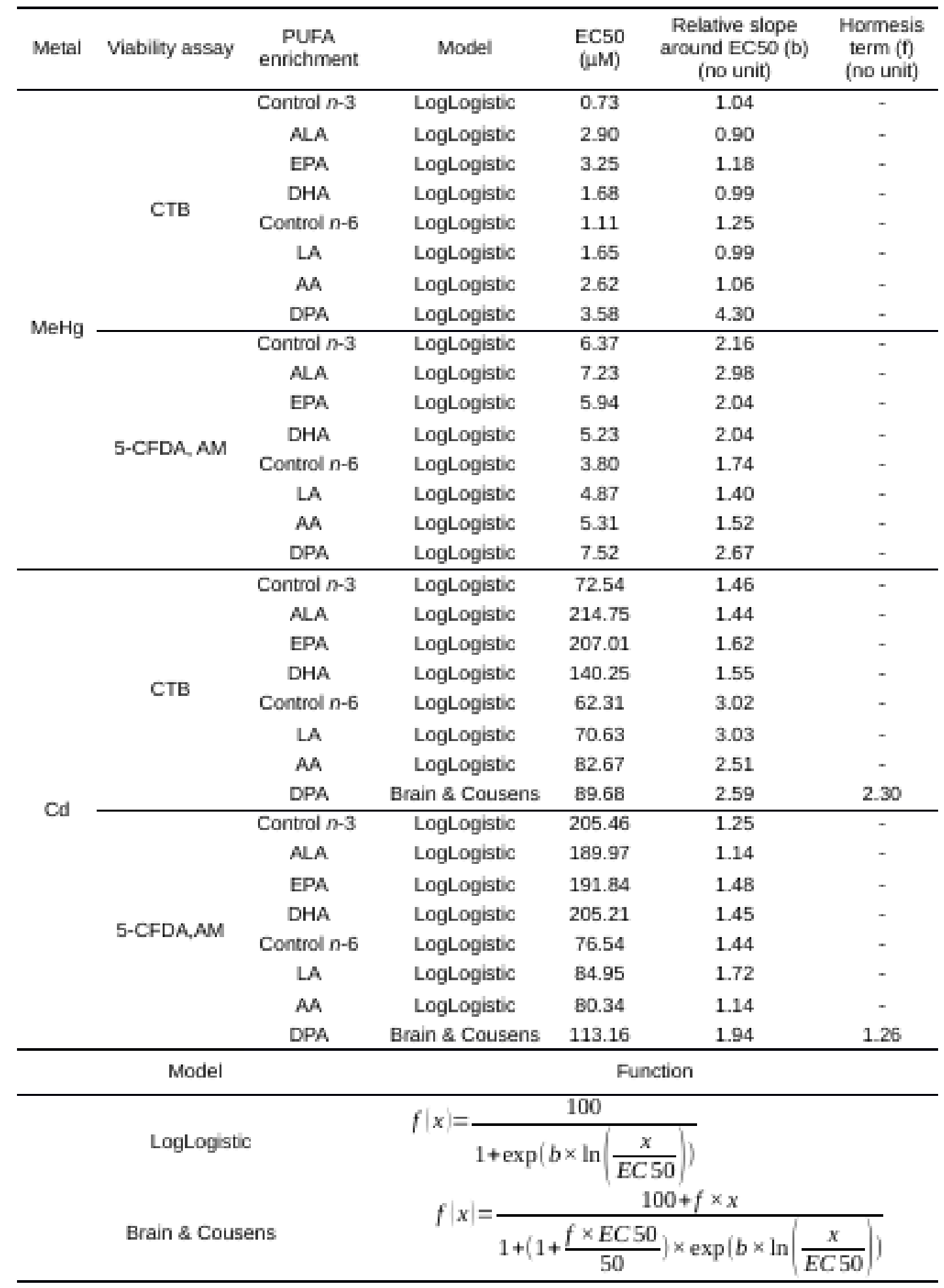




\section{SUPPLEMENTARY FIGURE 1}
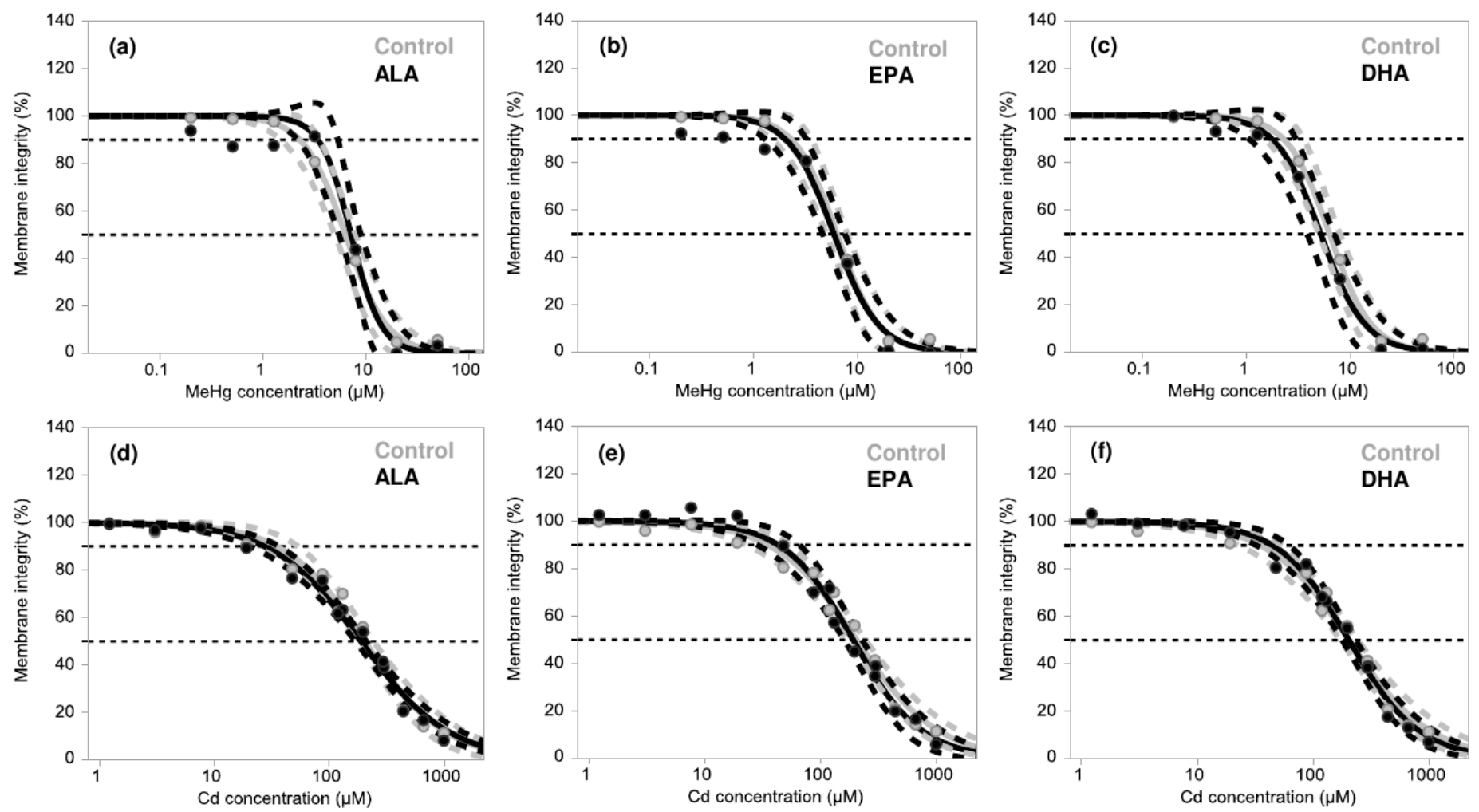

S.Fig. 1: Membrane integrity of the RTL-W1 cells enriched (black) or not (grey) in a specific n-3 PUFA (ALA, EPA or DHA) and challenged with increasing concentrations of $\mathrm{MeHg}(a-c)$ or $\mathrm{Cd}(\mathrm{d}-f)$ during 24 h.Plain curves represent the LogLogistic prediction models; dotted curves represent the confidence intervals at $98.3 \%$ for the predictions. Points represent the mean membrane integrities of the cells challenged at specific $\mathrm{MeHg}$ or Cd concentrations ( $n=3)$.Abbreviation used: ALA, alpha-linolenic acid; EPA, eicosapentaenoic acid; DHA, docosahexaenoic acid; MeHg, methylmercury; Cd, cadmium. 


\section{SUPPLEMENTARY FIGURE 2}
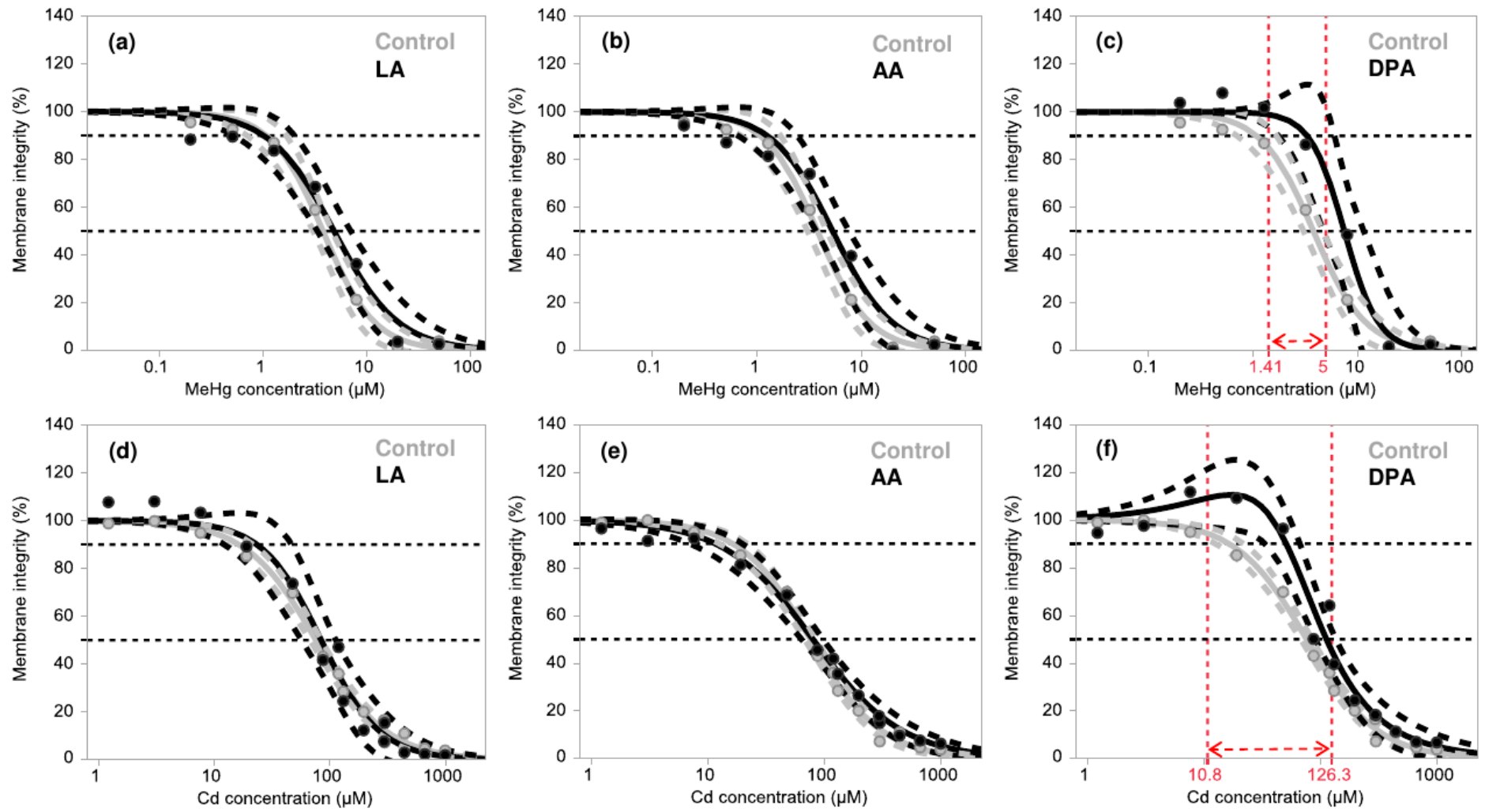

S.Fig. 2: Membrane integrity of the RTL-W1 cells enriched (black) or not (grey) in a specific n-6 PUFA (LA, AA or DPA) and challenged with increasing concentrations of $\mathrm{MeHg}(a-c)$ or $\mathrm{Cd}(d-f)$ during $24 \mathrm{hPlain}$ curves represent the LogLogistic or Brain \& Cousens prediction models; dotted curves represent the confidence intervals at $98.3 \%$ for the predictions. Points represent the mean membrane integrities of the cells challenged at specific MeHg or Cd concentrations ( $n=3$ or 4$)$. The dotted arrows delimit the metal concentration ranges within which the predicted membrane integrity of cells enriched with a specific n-6 PUFA is significantly higher than that of the control cells. Abbreviation used: LA, linoleic acid; AA, arachidonic acid; DPA, docosapentaenoic acid; MeHg, methylmercury; Cd, cadmium. 